\title{
MAPEAMENTO DE PERIGOS E RISCOS DE INUNDAÇÃO: UMA ABORDAGEM SEMIQUANTITATIVA
}

\author{
Paulo Cesar FERNANDES DA SILVA \\ Eduardo de ANDRADE \\ Denise ROSSINI-PENTEADO
}

\begin{abstract}
RESUMO
O trabalho apresenta uma abordagem semiquantitativa envolvendo a determinação de escores numéricos para o mapeamento de perigos e riscos de inundações e processos correlatos (enchentes, alagamentos, enxurradas), desenvolvida e aplicada em diferentes municípios do Estado de São Paulo (sudeste do Brasil). A análise de perigo busca identificar a probabilidade de ocorrência dos eventos de inundação, sua distribuição espacial e potencial magnitude. A setorização de risco incorpora a análise do uso e ocupação do solo para avaliar a vulnerabilidade dos diferentes elementos (por exemplo, edificações residenciais, equipamentos e instalações industriais, vias) aos processos geodinâmicos, conduzindo à delimitação de setores e à determinação empírica de intervalos de valores numéricos que indicam o grau de risco associado a cada setor. A estimativa de danos potenciais qualifica o risco no setor, expressando as possíveis perdas humanas, materiais e econômicas, em termos de número de moradias e moradores, equipamentos (indústrias, galpões e hospitais, entre outros) e extensão de vias com probabilidade de serem atingidas pelos eventos de inundação e processos correlatos. A aplicação do método em 7 municípios no Vale do Rio Paraíba do Sul (leste do Estado) permitiu a identificação e caracterização de 85 áreas de risco, abrangendo 5.257 moradias, 34 grandes equipamentos (escolas, parques, espaços poliesportivos, galpões industriais-comerciais, indústrias e minerações), e cerca de $20 \mathrm{~km}$ de vias. Em São José do Rio Preto (noroeste do Estado), foram identificadas 11 áreas de risco, totalizando 104 moradias, 95 estabelecimentos comerciais, 5 grandes equipamentos (incluindo Biblioteca Municipal, Rodoviária e Estação de Trem), e aproximadamente $10 \mathrm{~km}$ de vias. Dados tabulares e mapas de perigo e de risco referentes aos municípios de Guaratinguetá (Vale do Rio Paraíba do Sul) e de São José do Rio Preto são apresentados para exemplificar os resultados obtidos e a aplicabilidade do método proposto em contextos geomorfológicos, hidrodinâmicos e socioeconômicos distintos. A atribuição de escores numéricos permite a análise comparativa e hierarquização entre setores de perigo e de risco situados num mesmo município ou em municípios distintos, o que sugere sua aplicabilidade tanto no gerenciamento das situações de risco e resposta à emergência quanto ao planejamento urbano.
\end{abstract}

Palavras-chave: inundação, classificação de riscos, dano potencial, escores numéricos.

\section{ABSTRACT}

MAPPING OF FLOODING HAZARDS AND RISKS: A SEMIQUANTITATIVE APPROACH. This paper describes a semi-quantitative approach involving the determination of numerical scores for the mapping of flooding hazards and risks (and related phenomena such as flash flooding and ponding), which was developed and applied in different municipalities of the State of São Paulo (Southeastern Brazil). Hazard assessment and zoning require ways of estimating the probability of flooding phenomena as well as their potential spatial distribution and magnitude. Risk assessment procedures incorporate land use analysis to estimate the vulnerability of different elements (or features), including housing, urban equipment (such as industry, 
hospitals, etc.), and transportation infrastructure. This leads to the delineation of risk zones and a range of numerical values that indicate the severity of risks of each zone. Estimation of potential damage is meant to qualify the risk in the respective zone, thus expressing possible losses (regarding human lives, materials and economy), in terms of number of dwellings and dwellers, urban equipment and facilities (industry settlements, mining sites, hospitals, etc.), and the extent of roads to be affected by flooding and related phenomena. The application of the method in seven municipalities situated in the Paraíba do Sul River Valley (eastern São Paulo) has allowed the identification and characterization of 85 areas of risk, involving 5,257 dwellings, 34 major urban equipment and facilities (schools, public parks, sport facilities, industrial and mining sites, industry-commercial storage facilities), and approximately $20 \mathrm{~km}$ of roads and streets. In São José do Rio Preto (northwestern São Paulo) 11 areas of risk were identified, totaling 104 dwellings, 95 services and commercial facilities, and 5 urban equipments including the main public library, bus and train Stations, plus about $10 \mathrm{~km}$ of roads and streets. Tables of data and hazard and risk zoning maps from Guaratinguetá (Paraíba do Sul River Valley) and São José do Rio Preto are presented as examples of the results achieved and the applicability of the proposed approach in distinct geomorphological, hydrodynamic, and socio-economic contexts. Assessment based on numerical scores allows comparative analyses and ranking between hazard and risk zones situated in the same and in different municipalities, which will be useful for the management of existing situations of risk, emergency response and urban planning.

Keywords: flooding, risk classification, potential damage, numerical scores.

\section{INTRODUÇÃO}

Os fenômenos de inundação têm ocorrido com intensidade e frequência crescentes em áreas urbanas e causado perda de vidas humanas e significativos prejuízos econômicos. O processo de urbanização nas proximidades de rios e corpos d'água, em geral, somados à ausência de planejamento e ordenamento territorial, são alguns dos fatores que tem agravado os efeitos desses fenômenos nas últimas décadas, não apenas no Brasil, mas em diversas regiões do mundo, em particular nos países em desenvolvimento (MAFFRA \& MAZZOLA 2007, JHA et al. 2012). No Estado de São Paulo as inundações atingiram 235 municípios no período entre 2001 e 2011, e corresponderam a aproximadamente $64 \%$ de todas as ocorrências de desastres naturais registradas no estado (BROLLO et al. 2011, FERREIRA et al. 2011) (Figura 1). Nesse contexto, o Decreto $\mathrm{n}^{\circ}$ 57.512/2011 estabeleceu o Programa Estadual de Prevenção de Desastres Naturais e de Redução de Riscos Geológicos (PDN), que procura articular as estratégias de planejamento de uso e ocupação do solo e de planejamento ambiental com as ações de gestão de risco e defesa civil, o que inclui o diagnóstico de áreas sujeitas a escorregamentos, inundações, erosão e colapso de solo, e a adoção de intervenções estruturais (obras civis) e não estruturais (monitoramento, gerenciamento de emergências). Posteriormente, na esfera federal, foi aprovada e promulgada a Lei de Proteção e Defesa Civil (Lei Federal n ${ }^{\circ}$ 12.608/2012).

Tomando-se, por exemplo, as metodologias adotadas em GRAMANI et al. (2004), BRASIL (2007), IG (2008), MARCHIORI-FARIA et al. (2005) e MIRANDOLA et al. (2014) para a execução de trabalhos de mapeamento de risco de movimentos de massa e inundações, observa-se que a maioria dos estudos utiliza métodos qualitativos. De forma geral, esses métodos estão fundamentados em evidências de campo e no registro de ocorrências, apoiado no relato de moradores, e na estimativa do risco, com base em critérios subjetivos e/ ou na experiência profissional. Apesar de sua razoável eficácia para o gerenciamento de emergências e a convivência com situações de risco, verifica-se que os resultados dos mapeamentos de risco têm aplicação limitada para estimar impactos econômicos e para priorizar ações que requeiram intervenções estruturais (obras civis) voltadas à mitigação e remediação, o que é importante para os tomadores de decisão e formuladores de políticas públicas. Como apontado por BRANDÃO DA SILVA \& MENDONÇA (2007), a aplicação de métodos qualitativos de cartografia de risco na cidade do Rio de 
(A)

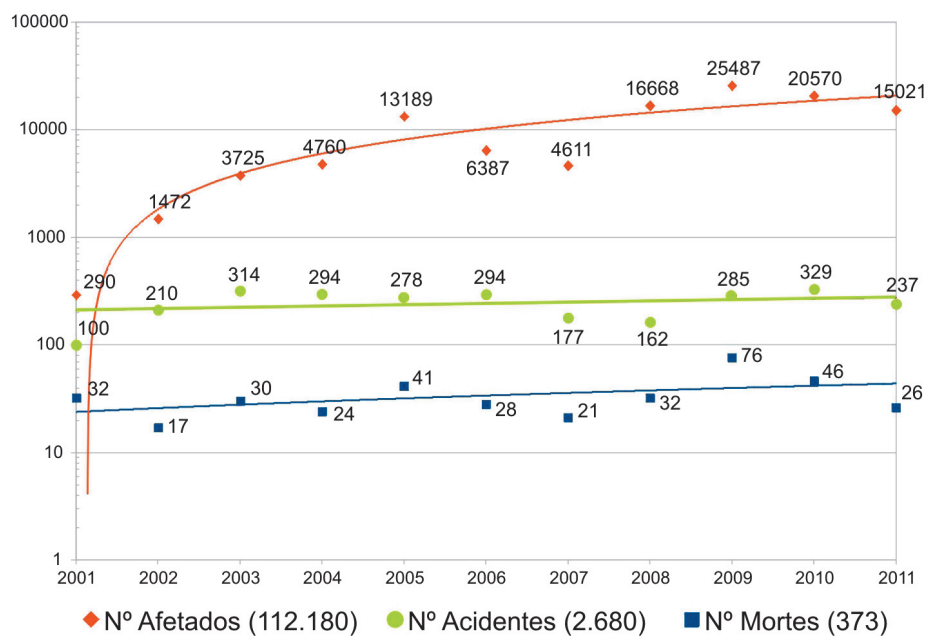

(B)

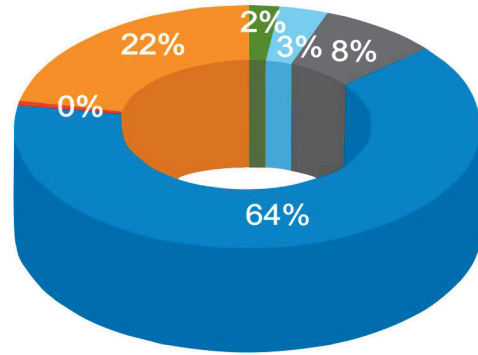

Granizo

Tempestades

Subsidência solo

Erosão

Inundação

FIGURA 1 - (A) Estatística dos desastres ocorridos no Estado de São Paulo no período de 2001 a 2011 (modificado de BROLLO et al. 2011). (B) Distribuição dos tipos de eventos ocorridos no Estado de São Paulo no período de 1 de janeiro a 15 de março de 2011 (modificado de FERREIRA et al. 2011).

Janeiro levaram à interpretação e classificação de extensas áreas como zonas de alta suscetibilidade e/ou de alto risco de escorregamentos, o que levou os autores a proporem um Índice Quantificador de Risco (IQR) como ferramenta para hierarquização do risco e eliminação de critérios subjetivos na priorização de medidas mitigadores e realização de intervenções estruturais.

A forma como os fenômenos de inundação atingem e afetam as populações e a infraestrutura urbana é distinta dos movimentos gravitacionais de massa (ex. escorregamentos), uma vez que apresentam uma distribuição espacial ampla e sua ocorrência pode não estar diretamente ligada à pluviosidade local, podendo abranger extensas áreas e desabrigar e/ou desalojar um grande número de pessoas, causando vultosos impactos econômicos e sociais (JHA et al. 2012).

$\mathrm{O}$ artigo apresenta uma abordagem semiquantitativa - em escala local (1:3.000) - voltada ao mapeamento de perigos e riscos de inundações em municípios do Vale do Rio Paraíba do Sul (Aparecida, Roseira, Tremembé, Pindamonhangaba, Guaratinguetá, Caçapava e Taubaté), porção leste do Estado de São Paulo, e no município de São José do Rio Preto - noroeste do Estado (Figura 2). O trabalho contempla uma demanda estabelecida pelo significativo número de ocorrências de inundação, particularmente na porção leste do Estado, que indica a necessidade de estudos para orientar a ação efetiva do Poder Público no âmbito do PDN. Além disso, a escolha dessas áreas buscou o desenvolvimento do método e sua aplicabilidade em contextos geomorfológicos, hidrográficos e socioeconômicos distintos.

A ocupação urbana e a atividade econômica dos municípios do Vale do Paraíba, com destaque à indústria e extração mineral de agregados para a construção civil, estão associadas à longa e extensa planície do Rio Paraíba do Sul, com altitudes entre 530 e $550 \mathrm{~m}$, desenvolvida sobre uma bacia sedimentar cenozoica (Bacia de Taubaté). O Vale do Paraíba segue as direções das estruturas geológicas regionais, encaixado entre unidades de relevo do Planalto Atlântico (designações locais Serra da Mantiqueira, Serra da Bocaina, Planalto de Paraitinga-Paraibuna), constituídas por rochas granítico-gnáissicas, com formas denudacionais de escarpas e morros altos, com topos aguçados e convexos, altimetrias entre 800 e 2.000 m e declividades superiores a 20\% (ROSS \& MOROZ 1997).

Por sua vez, o município de São José do Rio Preto está localizado na porção nordeste da Bacia Sedimentar do Paraná, no "Planalto Ocidental Paulista", onde as formas de relevo predominantes são as colinas amplas e médias de topos aplainados, altimetrias variando entre 400 e $700 \mathrm{~m}$, e declividades médias entre 2 e 10\% (ROSS \& MOROZ 1997). O município está inserido nas bacias hidrográficas dos rios Turvo e Grande e tem como prin- 
cipais cursos d'água o Rio Preto e seus afluentes (córregos Borá, Canela e Piedade). A declividade local não é acentuada e, portanto, não cria condições para a ocorrência de elevados índices de escoamento superficial. Todavia os registros históricos e relatos da defesa municipal mostram a ocorrência frequente de processos de enxurra$\mathrm{da}$, particularmente associados às grandes vias e aos córregos tributários do Rio Preto que foram canalizados e cortam o munícipio, devido à impermeabilização dos terrenos e deficiências da drenagem urbana. A atividade econômica está fortemente ligada à agroindústria e a maior parte da mancha urbana corresponde a uma ocupação mista formada por edificações residenciais, comércio e serviços.

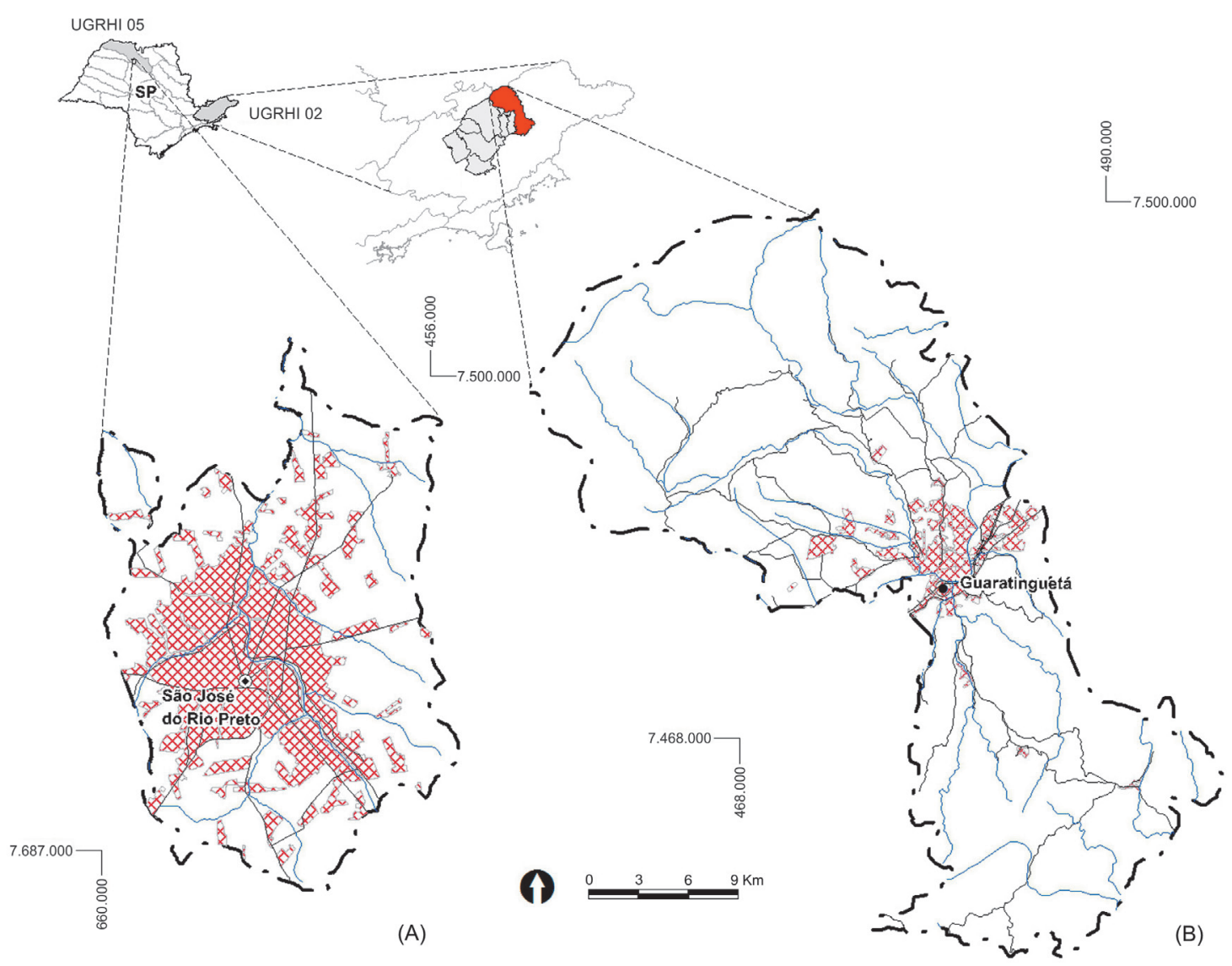

FIGURA 2 - Localização das áreas de estudo no Estado de São Paulo. Estão assinaladas as bacias hidrográficas dos rios Turvo e Grande (UGRHI 15), onde está situado o município de São José do Rio Preto (A), e a Bacia Hidrográfica do Rio Paraíba do Sul (UGRHI 02), com destaque para os municípios de Aparecida, Roseira, Tremembé, Pindamonhangaba, Caçapava, Taubaté e Guaratinguetá (em detalhe, B) (modificado de IG 2012a, b). Coordenadas UTM - Zonas 22K e 23K, respectivamente.

\section{MÉTODOS E ETAPAS DE TRABALHO}

Os estudos dos fenômenos de inundação e processos correlatos em áreas urbanas, em particular o zoneamento de áreas inundáveis, são direcionados principalmente a dois tipos de ações: a) incorporação de parâmetros de risco aos instrumentos de planejamento e de gestão do desenvolvimento urbano; b) implementação e operacionalização de mecanismos de resposta à emergência e de gerenciamento de situações de risco já existentes, incluindo medidas de controle para mitigação e remediação dos impactos bem como sistemas de monitoramento, previsão e alerta (TUCCI 2005, CORREA et al. 2011, JHA et al. 2012).

A terminologia proposta em BRASIL (2007) foi adotada para diferenciar os fenômenos de caráter hidrometeorológico relacionados mais diretamente a hidrodinâmica fluvial, como inundação e enchente, dos processos correlatos, tais como 
alagamentos e enxurradas, termos usualmente empregados no estudo de áreas urbanas, podendo ter ou não relação com processos de natureza fluvial. As enchentes ou cheias são definidas como a elevação do nível d'água no canal de drenagem devido ao aumento da vazão, que atinge a cota máxima do canal, porém, sem extravasamento. A inundação diz respeito ao extravasamento (ou transbordamento) das águas de um curso d'água atingindo a planície aluvial (ou de inundação), ou, como proposto em TUCCI (2005), é o fenômeno que ocorre quando o escoamento atinge níveis superiores à capacidade do leito menor, atingindo $o$ leito maior, que frequentemente é ocupado pelas populações em áreas urbanas, causando impactos adversos e resultando em áreas de risco. De acordo com o tempo de concentração das vazões no canal da drenagem e a velocidade de escoamento do fluxo, as inundações podem ser classificadas como graduais ou súbitas (inundações relâmpago, cabeça d'água ou flashflood). Os alagamentos são compreendidos como o acúmulo momentâneo de águas em determinados locais (em geral, decorrentes do escoamento pluvial), por deficiência no sistema de drenagem. Os processos de enxurrada decorrem do escoamento superficial concentrado e com alta energia de transporte ao longo de encostas, sem que haja necessariamente um canal de drenagem ou área rebaixada associada. O termo "enxurrada" é, por vezes, também utilizado para referir-se às inundações súbitas.

De acordo com o Guia Metodológico para Elaboração de Cartografias de Riscos Naturais da Espanha (ESPANHA 2008), os métodos de análise de perigo e de risco de inundações podem ser agrupados em três tipos principais que, muitas vezes, são empregados de forma combinada e complementar: métodos histórico-paleohidrológicos, métodos geológico-geomorfológicos e métodos hidrológico-hidráulicos. Dentre estes, com pertinência para a metodologia descrita no presente trabalho, destacam-se os métodos históricos, que empregam marcas deixadas em elementos artificiais (edificações, postes e torres de transmissão de energia elétrica, vias etc) ou naturais (taludes de margem, vegetação, etc.), documentação histórica (manuscritos e impressos de arquivos, bibliotecas, hemerotecas) e testemunhos (orais e audiovisuais) para reconstituir a extensão e a cota alcançada pelas águas em eventos pretéritos. Numa aplicação simples deste método assume-se que os níveis alcançados pela água no passado também poderão ser alcançados num futuro não muito distante.
Os métodos geológico-geomorfológicos utilizam a disposição e a tipologia das formas do terreno e os depósitos sedimentares gerados durante um evento de cheia para delimitar as áreas ativas do canal de drenagem e suas margens, e, portanto, as áreas suscetíveis às inundações no contexto da hidrodinâmica fluvial, procurando inferir parâmetros como a profundidade, a velocidade de corrente e carga sólida transportada.

Os métodos hidrológico-hidráulicos tratam da estimativa de vazões em uma bacia ou do cálculo de velocidade e profundidade do fluxo hidrodinâmico num determinado trecho fluvial. Segundo PINHEIRO (2003), os modelos de previsão de cheias enfocam a propagação do escoamento superficial em função dos índices pluviométricos (em geral, média de precipitação total de chuva na bacia contribuinte), buscando estimar os níveis da água ou vazões futuras para determinado instante de tempo e condições específicas. Tais modelos subdividem-se em conceituais e empíricos. Os modelos conceituais baseiam-se no conhecimento físico e na caracterização da bacia hidrográfica, buscando integrar as análises do regime hídrico, os problemas de uso e ocupação do solo e o sistema socioeconômico. Os modelos empíricos buscam inferir as relações entre o fluxo hidrodinâmico de entrada e saída da bacia a partir de dados observados. Neste último grupo destacam-se os modelos estocásticos, que procuram modelar as séries de vazões de acordo com leis de probabilidade (previsão de vazões a partir de medidas realizadas ao longo do tempo). Por outro lado, deve ser observado que o levantamento (gestão) de dados e informações por meio de monitoramentos meteorológicos e hidrológicos, necessários à previsão de cheias, é pouco comum no Brasil.

A abordagem semiquantitativa aqui apresentada utiliza a abordagem histórica, combinando e adaptando os modelos conceitual e empírico de previsão de cheias aos propósitos do mapeamento de risco, onde o objetivo não é aferir diretamente a vazão, mas estimar a abrangência espacial da inundação (em termos de extensão) e sua magnitude (em termos de recorrência dos eventos, profundidade da água nos trechos atingidos e potenciais danos), de forma a direcionar os resultados às medidas de controle das áreas urbanas inundáveis a partir do zoneamento do território, como indicado em TUCCI (2005). Nesse sentido, como forma de suprir a ausência de dados contínuos e consistentes de pluviometria e fluviometria, a análise e setorização do perigo adotam parâmetros, tais como o nível efetivamente atingido ou potencialmente atingível 
pela água nos diferentes locais $(N A t)$ e o histórico de ocorrências dos fenômenos de inundação num determinado intervalo de tempo, sem procurar estimar o tempo de retorno dos eventos.

O trabalho teve como premissas a base conceitual para avaliação de risco e desastres apresentada em VARNES (1984), UN-ISDR (2004, 2009) e TOMINAGA (2009), bem como as proposições de ROSSINI-PENTEADO et al. (2007) para quantificação da vulnerabilidade aplicada à análise de risco, valendo-se de recursos técnicos como o uso de bases de dados de livre acesso disponíveis na Internet, produtos de sensores orbitais e aéreos, geoprocessamento e, em alguns casos específicos, técnicas de análise espacial de dados por meio de modelagem determinística e geoestatística (DRUCK et al. 2004).

As etapas de trabalho compreenderam: a) levantamento preliminar e cadastro georreferen- ciado de ocorrências de inundação; b) seleção de áreas-alvo e trabalhos de campo; c) delimitação e caracterização de setores de perigo; d) análise de uso e ocupação do solo para estimativa de vulnerabilidade; e) delimitação e classificação de setores de risco; f) estimativa de dano potencial. Em termos de produtos e resultados, o mapeamento em escala local (1:3.000) consiste em delimitar setores (ou zonas) de perigos e de riscos específicos para inundação (e processos correlatos), classificados de acordo com sua criticidade por meio da atribuição de um grau de perigo/risco. Os setores são o resultado da delimitação e classificação de porções do território segundo as características da dinâmica, abrangência e temporalidade dos eventos esperados e do uso e ocupação do solo. O termo área de risco, empregado no presente estudo, compreende um setor ou um conjunto de setores geralmente relacionados a uma mesma localidade

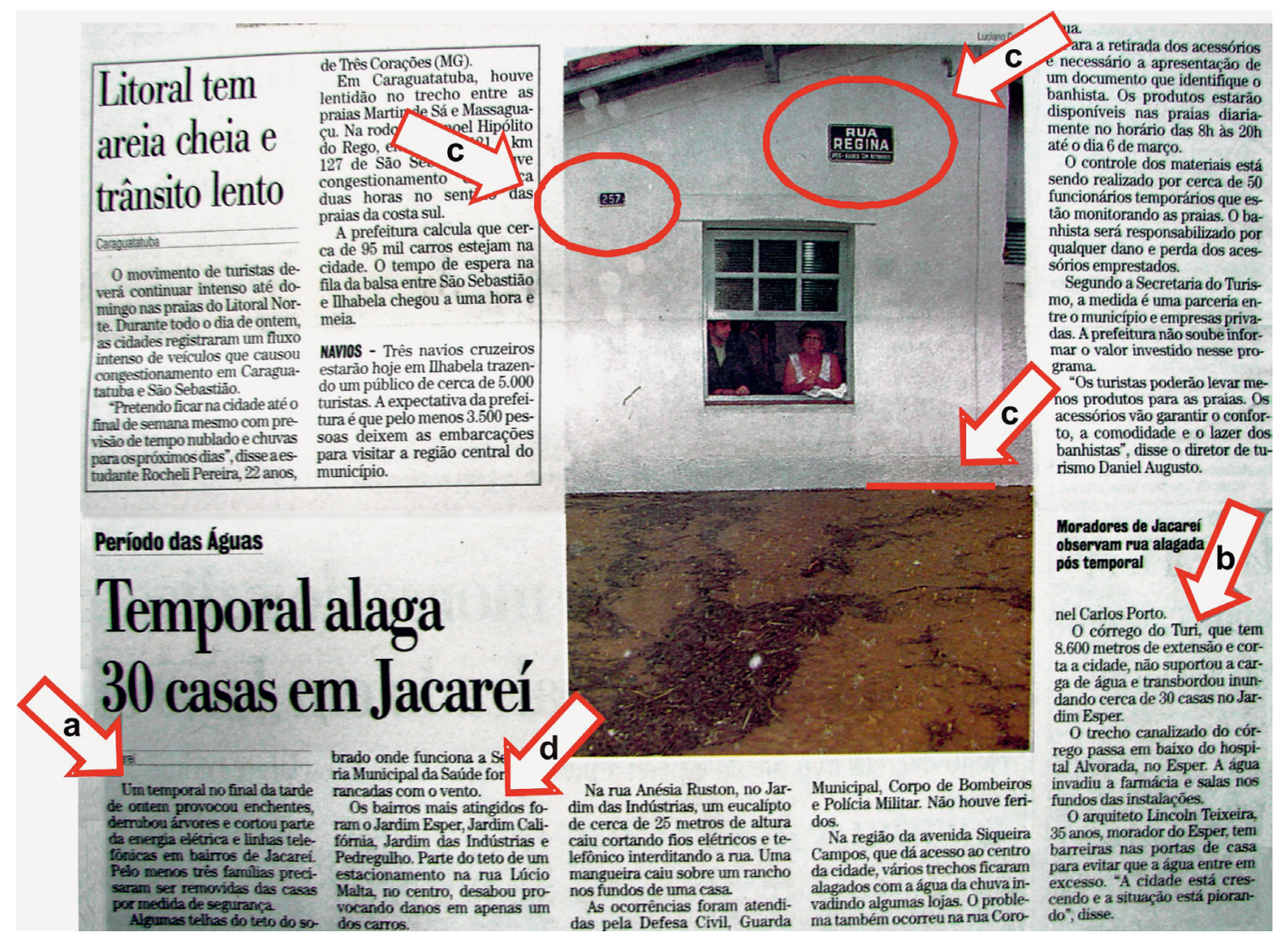

FIGURA 3 - Exemplo de dados e informações coletados em notícias publicadas na mídia impressa. Dentre as informações pertinentes, destacam-se: a) o tipo de evento (enchente, inundação, alagamento); b) a drenagem associada (nome do curso d'água - rio, córrego, ribeirão); c) os locais e áreas afetadas (cidades, rodovias, bairros - no caso específico da foto, endereço exato com nome da rua e número, bem como o nível atingido pela água); d) a extensão dos danos ( $n^{\circ}$ de moradias/edificações atingidas). Fonte: Jornal Valeparaibano, ed. 14.299, 03 de novembro de 2003, p. 12. 
(bairro), onde há possibilidade de ocorrência de processos com potencial para causar danos tangíveis diretos e indiretos (materiais e econômicos) e/ ou intangíveis (população afetada, perda de vidas, problemas de saúde, danos sociais e psicológicos). Detalhes sobre conceituação e estimativas de danos relacionados aos fenômenos de inundação são discutidos nos trabalhos de MEYER \& MESSNER (2005) e DIAS et al. (2014).

2.1 Levantamento preliminar e cadastro georreferenciado de ocorrências de inundação

A primeira etapa do trabalho inclui o levantamento de todas as informações sobre o meio físico das áreas de estudo (Bacia Hidrográfica do Rio Paraíba do Sul e Sub-Bacia Hidrográfica do Rio Preto) e, em particular, a elaboração de um cadastro georreferenciado dos registros de inundações, enchentes, alagamentos e enxurradas publicados em jornais (ANDRADE et al. 2010) (Figura 3).

O Jornal Vale Paraibano foi utilizado como a principal fonte de pesquisa e coleta de dados sobre a Bacia Hidrográfica do Rio Paraíba do Sul devido a periodicidade diária, continuidade das edições e a abrangência temporal (Janeiro/1970 a Outubro/2009) e geográfica (registros referentes a todo o trecho de interesse). Na região de São José do Rio Preto, o veículo utilizado foi o Diário da Região, com um período aproximado de 10 anos de edições diárias disponíveis (Janeiro 2001 a Março 2011). Para a compilação final do cadastro georreferenciado foram acrescentados registros provenientes da Coordenadoria Estadual de Defesa Civil (CEDEC) e das Coordenadorias Municipais de Defesa Civil (COMDECs). Na etapa de georreferenciamento dos dados foram utilizados os aplicativos Google Earth e Google Maps e as plantas cartográficas do Instituto Geográfico e Cartográfico (IGC), escala 1:10.000, dos municípios. Uma vez que as imagens disponíveis no Google Earth apresentam imprecisões cartográficas, procedeu-se a verificação e ajuste dos erros com o auxílio das bases cartográficas na escala 1:10.000. A figura 3 ilustra o processo de coleta de dados a partir de matérias jornalísticas veiculadas na mídia impressa.

A figura 4 apresenta uma comparação entre as séries históricas dos dados pluviométricos (acumulado anual de precipitação) de quatro estações pluviométricas localizadas no Município de Taubaté, com razoável abrangência temporal e continuidade dos dados, e os registros de eventos de inundação e processos correlatos levantados no município, no período de 1967 até 2004. Observa-se uma boa correlação entre os picos de maior precipitação e de maior número de registro de ocorrências nos anos de 1975-76, 1983, 1996, 1999 e 2002, como também nos casos opostos - nos anos de 1984, 1990, 2000 e 2004.

\subsection{Seleção de áreas-alvo e trabalhos de campo}

O cadastro georreferenciado das ocorrências é utilizado como principal ferramenta para orientar a escolha de áreas-alvo e os trabalhos de campo para detalhamento em escala local. Em alguns casos, novas áreas-alvo foram selecionadas em função de aspectos geomorfológicos locais, dinâmica espacial do fenômeno estudado in loco e dos relatos (oral e audiovisual) de moradores e agentes públicos municipais.

Nos trabalhos de campo os registros fotográficos e as medidas tomadas in situ (Figura 5) visam levantar parâmetros relacionados à drenagem (como por exemplo, largura do canal, altura dos taludes de margem, distância da ocupação até o talude de margem), aspectos inerentes aos fenômenos de inundação e ao histórico de ocorrências, bem como às características de uso e ocupação do solo (Tabela 1). Esta etapa envolve, ainda, a coleta junto aos agentes municipais e moradores das áreas de risco, de informações relacionadas à frequência, intensidade e abrangência espacial dos eventos de inundação.

\subsection{Análise de perigo à inundação $(\mathrm{P})$}

Os setores de perigo procuram expressar a probabilidade de ocorrência dos fenômenos de inundação, sua distribuição espacial (abrangência) e frequência num determinado intervalo de tempo. No presente trabalho foram adotados os procedimentos metodológicos descritos em FERNANDES DA SILVA et al. (2011) e ANDRADE et al. (2012) para o cálculo do grau de Perigo $(\mathrm{P})$ e a subsequente delimitação e caracterização dos setores. Para tanto foram considerados dois atributos (Tabela 2): (1) o nível estimado ou efetivamente atingido pela água (NAt) em diferentes locais; (2) o histórico de ocorrências num determinado intervalo de tempo, neste caso, 10 anos. O atributo NAt representa a diferença (aferida em unidades lineares, no caso, em metros) entre o nível de inundação e o terreno em um determinado episódio ou a probabilidade de ocorrência, como em DIAS et al. (2014). Os valores podem derivar de modelos hidrodinâmicos (2D e 3D), análises estatísticas ou, como no caso do presente estudo, da análise espacial de dados 


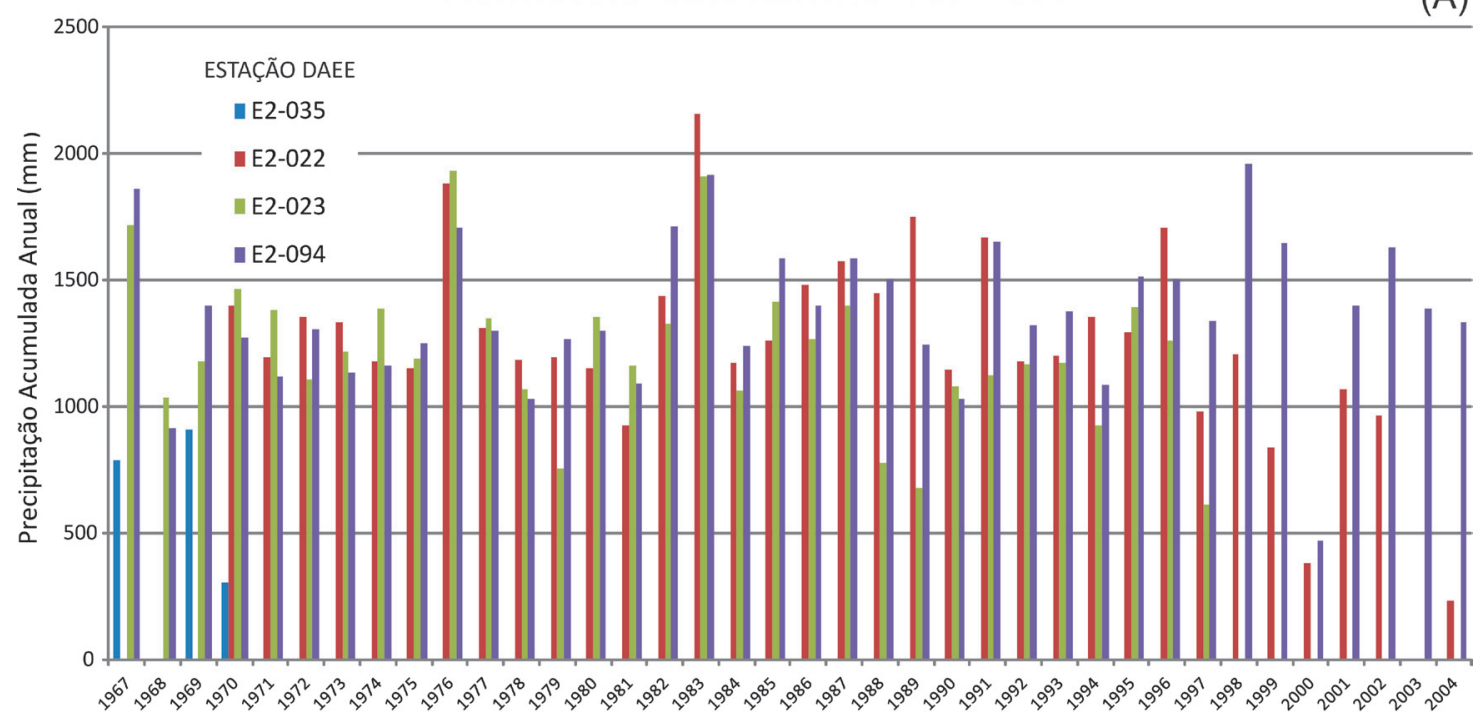

Registro de Ocorrências (Notícias de Jornais)- Período 1967 - 2004

(B)

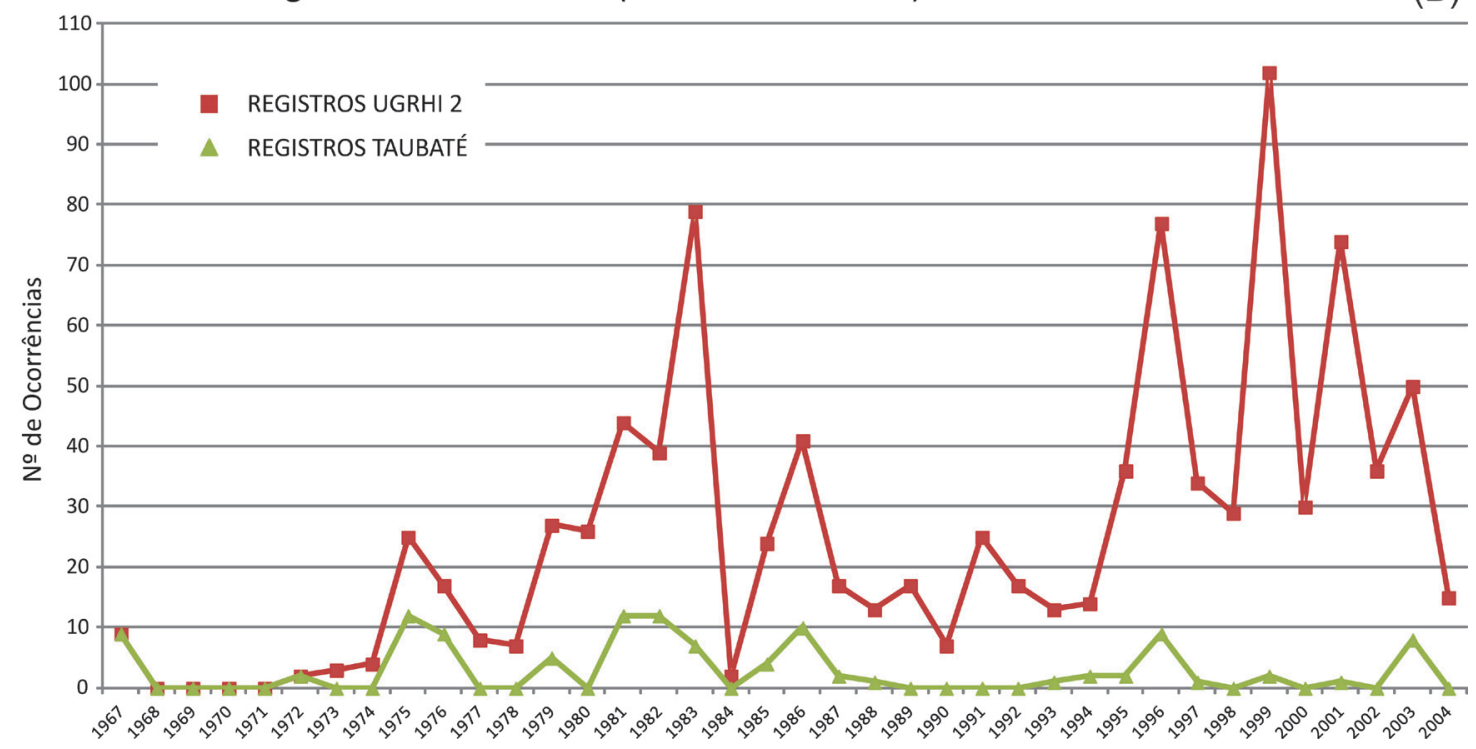

FIGURA 4 - Comparação entre as séries históricas de dados pluviométricos (acumulados anuais de precipitação) e os registros de ocorrências de eventos de inundação e processos correlatos. (A) Gráfico do acumulado de precipitação anual (período de 1967 a 2004), registrado por quatro estações pluviométricas selecionadas no município de Taubaté. Fonte: Departamento de Águas e Energia Elétrica - DAEE. (B) Gráfico do total anual das ocorrências de eventos de inundação e processos correlatos publicadas em jornal (período de 1967 a 2004) nos sete municípios do Vale do Paraíba (UGRHI 2) e para o Município de Taubaté.

e observações realizadas nas áreas inundadas, por meio de marcas deixadas em edificações diversas e outros elementos artificiais ou naturais, registros fotográficos e/ou audiovisuais durante um episódio de inundação coletados em jornais, órgãos do poder público e de informações da população.
A análise é efetuada em três estágios distintos, brevemente descritos a seguir: 1) obtenção de escores numéricos e classificação preliminar do perigo; 2) delimitação e caracterização dos setores de perigo; 3 ) aplicação de fatores de correção e reclassificação do grau de perigo. 


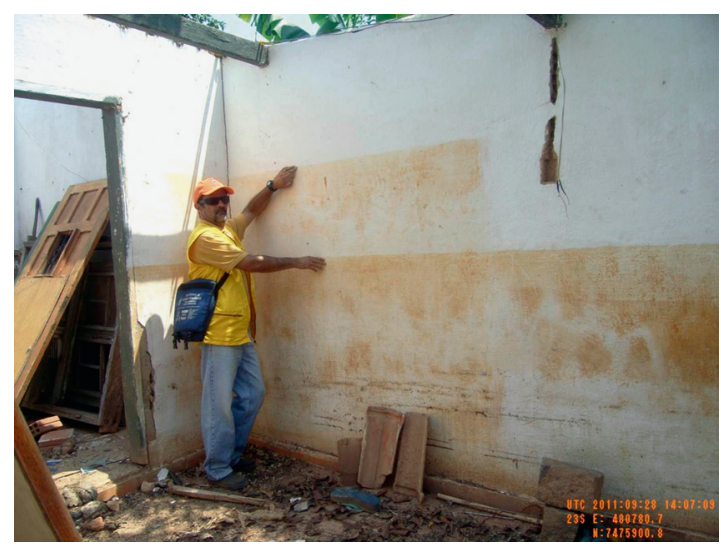

FIGURA 5 - Coleta de dados em trabalhos de campo. Níveis efetivamente atingidos pela água $(N A t) \mathrm{em}$ dois eventos distintos de inundação medidos a partir das marcas da água na parede de moradia, situada próximo à margem esquerda do Ribeirão São Gonçalo, município de Guaratinguetá.

2.3.1 Obtenção de escores numéricos e classificação preliminar do perigo

Para a classificação preliminar do perigo foram obtidos escores numéricos e estabelecidos quatro limiares de classes, a partir da análise estatística dos valores de NAt de 331 pontos de observação distribuídos pelos sete municípios contíguos da Bacia Hidrográfica do Rio Paraíba do Sul (Aparecida, Roseira, Tremembé, Pindamonhangaba, Guaratinguetá, Caçapava e Taubaté). Para cada classe atribuiu-se um escore numérico, na escala de 0 a 1 (Tabela 3 ), calculado pela razão entre a soma dos valores incluídos na respectiva classe e a soma total de valores de $N A t$ (normalização).

Os valores de limiares de classe do nível atingido pela água $(N A t)$, atribuídos de forma empírica no presente estudo $(0,40 \mathrm{~m} ; 0,80 \mathrm{~m} ; 1,20 \mathrm{~m}$ e $>1,20$ $\mathrm{m})$, demonstraram-se compatíveis com as classes batimétricas de zonas inundáveis de outros estudos de avaliação e cartografia de perigos, realizados em regiões com características bastante distintas como, por exemplo, em IPH (2001), MEYER \& MESSNER (2005), MERZ et al. (2007), ESPANHA (2008), DIAS et al. (2014). Nesse sentido, os valores apresentados na tabela 3 , numa primeira aproximação, foram utilizados em caráter experimental no município de São José do Rio Preto, ainda que num contexto geomorfológico e hidrodinâmico diferenciado do Vale do Rio Paraíba do Sul.

TABELA 1 - Características e aspectos do meio físico e da ocupação observados em campo.

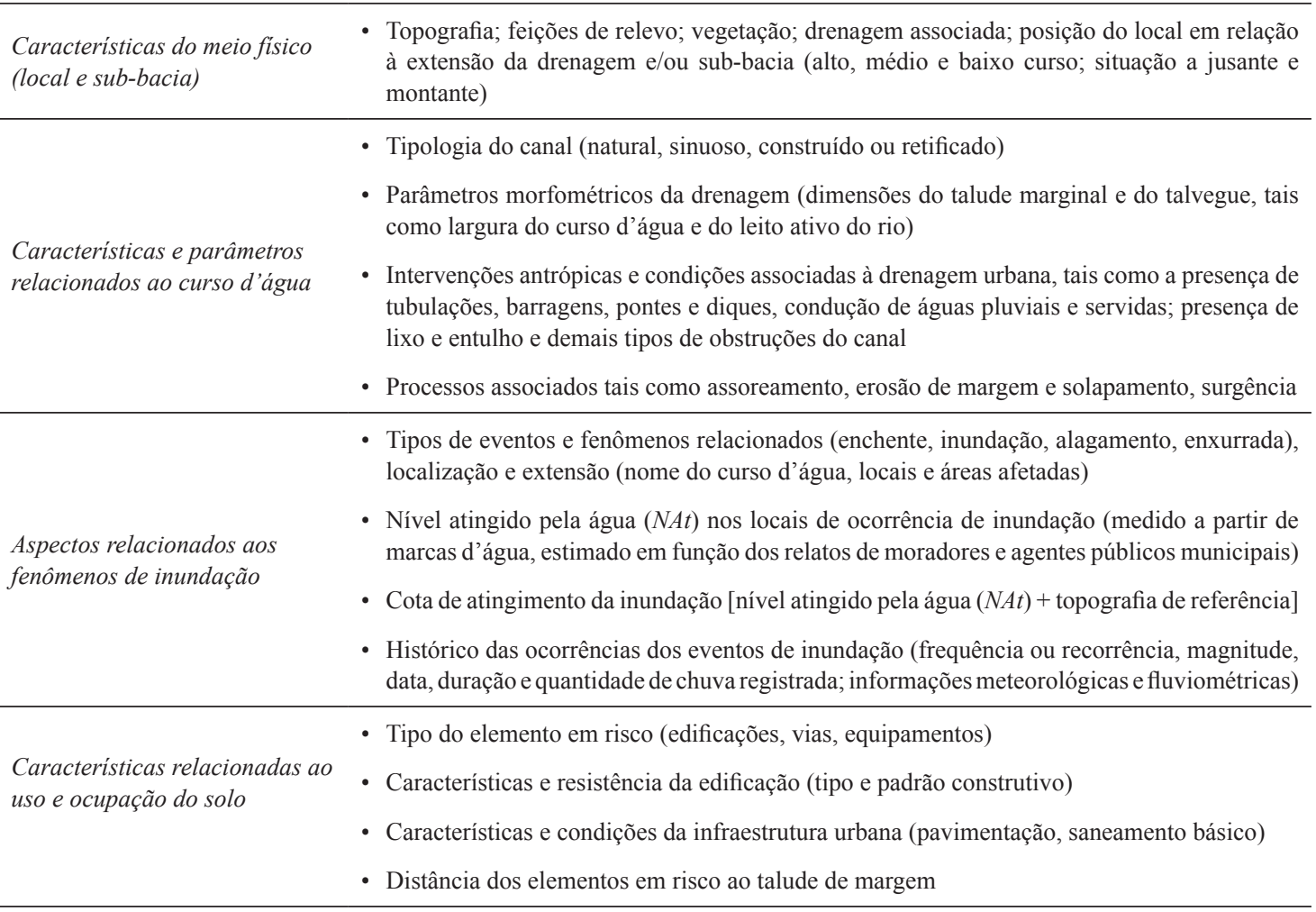


TABELA 2 - Atributos relacionados ao meio físico utilizados no cálculo da variável Perigo de inundação (P) na escala local.

\begin{tabular}{|c|c|c|}
\hline ATRIBUTO & DESCRIÇÃO & FORMA DE OBTENÇÃO \\
\hline $\begin{array}{l}\text { (NAt) Nivel de } \\
\text { Atingimento }\end{array}$ & $\begin{array}{l}\text { - Expressa o nível estimado ou efetivamente atingido pela água } \\
\text { no setor, considerando-se o histórico dos eventos anteriores e a } \\
\text { geomorfologia local } \\
\text { - Fonte: trabalhos de campo, relatos, bancos de dados, análise } \\
\text { geoespacial } \\
\text { - Unidade: metros } \\
\text { - Classes: } 0 \text { a } 0,40 \mathrm{~m} ; 0,40 \text { a } 0,80 \mathrm{~m} ; 0,80 \text { a } 1,20 \mathrm{~m} ;>1,20 \mathrm{~m}\end{array}$ & $\begin{array}{l}\text { a) Medido: a partir de marcas da água } \\
\text { observadas em campo } \\
\text { b) Inferido: a partir de relatos de mora- } \\
\text { dores e agentes municipais, notícias de } \\
\text { jornais e/ou análise geoespacial }\end{array}$ \\
\hline (Rec) Recorrência & $\begin{array}{l}\text { - Número de eventos registrados no setor, fornecendo uma indi- } \\
\text { cação da probabilidade de eventos futuros } \\
\text { - Fonte: notícias de jornais, bancos de dados, relatos } \\
\text { - Unidade: adimensional }\end{array}$ & $\begin{array}{l}\text { Determinado a partir de notícias de jor- } \\
\text { nais, cadastros de ocorrências e de rela- } \\
\text { tos de moradores e agentes municipais }\end{array}$ \\
\hline
\end{tabular}

TABELA 3 - Classificação do Perigo Preliminar (Pp) de inundação em função do nível de atingimento (NAt).

\begin{tabular}{ccc}
\hline NAt & $\begin{array}{c}\text { Escore } \\
\text { Preliminar }\end{array}$ & $\begin{array}{c}\text { Perigo Preliminar } \\
(P p)\end{array}$ \\
\hline$N A t<0,40 \mathrm{~m}$ & 0,1072 & Pp1 - Baixo \\
$0,40<N A t<0,80 \mathrm{~m}$ & 0,4226 & $\mathrm{Pp} 2$ - Moderado \\
$0,80<N A t<1,20 \mathrm{~m}$ & 0,7042 & Pp3 - Alto \\
$N A t>1,20 \mathrm{~m}$ & 1,0000 & Pp4 - Muito Alto \\
\hline
\end{tabular}

2.3.2 Delimitação e caracterização de setores de perigo

A setorização de perigo de inundação, numa primeira avaliação, tem por finalidade delimitar a abrangência espacial de cada uma das classes de nível de atingimento (NAt) definidas na classificação preliminar. Para a delimitação e a caracterização dos polígonos ou setores de perigo são combinados: a) as informações dos trabalhos de campo (registros fotográficos e observações diversas - Tabela 1); b) os procedimentos de interpretação visual de imagens (satélite e ortofoto), enfocando feições geomorfológicas locais e do canal de drenagem, a partir das propriedades de sombreamento, textura e tonalidade das imagens; c) a análise das curvas de nível das cartas topográficas em formato digital (IGC - escala 1:10.000 e/ou IBGE - escala 1:50.000); d) a análise espacial de dados, em casos específicos, onde a disponibilidade e confiabilidade dos dados permitiram a geração de grades numéricas de valores interpolados dos valores de NAt e de cota de atingimento (cota altimétrica de referência $+N A t$ ). Para alguns municípios, foram adotados modelos determinísticos locais (média ponderada) e geoestatísticos (krigagem) para a geração de superfícies de interpolação, com grades numéricas regulares dos valores de cotas de atingimento e do nível da água atingido nos locais de ocorrência $(N A t)$ em intervalos de $0,10 \mathrm{~m}$ (Figura 6). Como sugerido por FERNANDES DA SILVA et al. (2011) e ANDRADE et al. (2012), técnicas de interpolação podem ser utilizadas com o objetivo de adensar a cobertura do mapeamento e aumentar a capacidade de interpretação.

2.3.3 Aplicação de fatores de correção e reclassificação do grau de perigo

A classificação preliminar do grau de perigo foi objeto de revisão dos escores em função do número de ocorrências (recorrência) dos fenômenos em cada setor analisado. Nesse caso, aplicaram-se os fatores de correção $(F c)$ definidos com base na análise matemática (séries convergentes) dos intervalos entre os limiares de classe do perigo preliminar, de forma a preservar a lógica e coerência do processo de quantificação e classificação.

Como indicado na tabela 4 , a redução do escore ocorre quando a delimitação do setor se faz exclusivamente a partir da interpretação de imagens, combinada à análise das curvas nível ou aos valores interpolados de NAt e da cota de atingimento (em alguns casos específicos, como descrito no item 2.3.2). Quando os trabalhos de campo permitem verificar a existência de pelo menos um ponto de ocorrência dentro de um setor, sem recorrências, o escore é mantido. No caso do registro de recorrência dos eventos aplicam-se os fatores de correção, o que eleva o escore atribuído preliminarmente e, consequentemente, determina a elevação do grau de perigo na maioria 


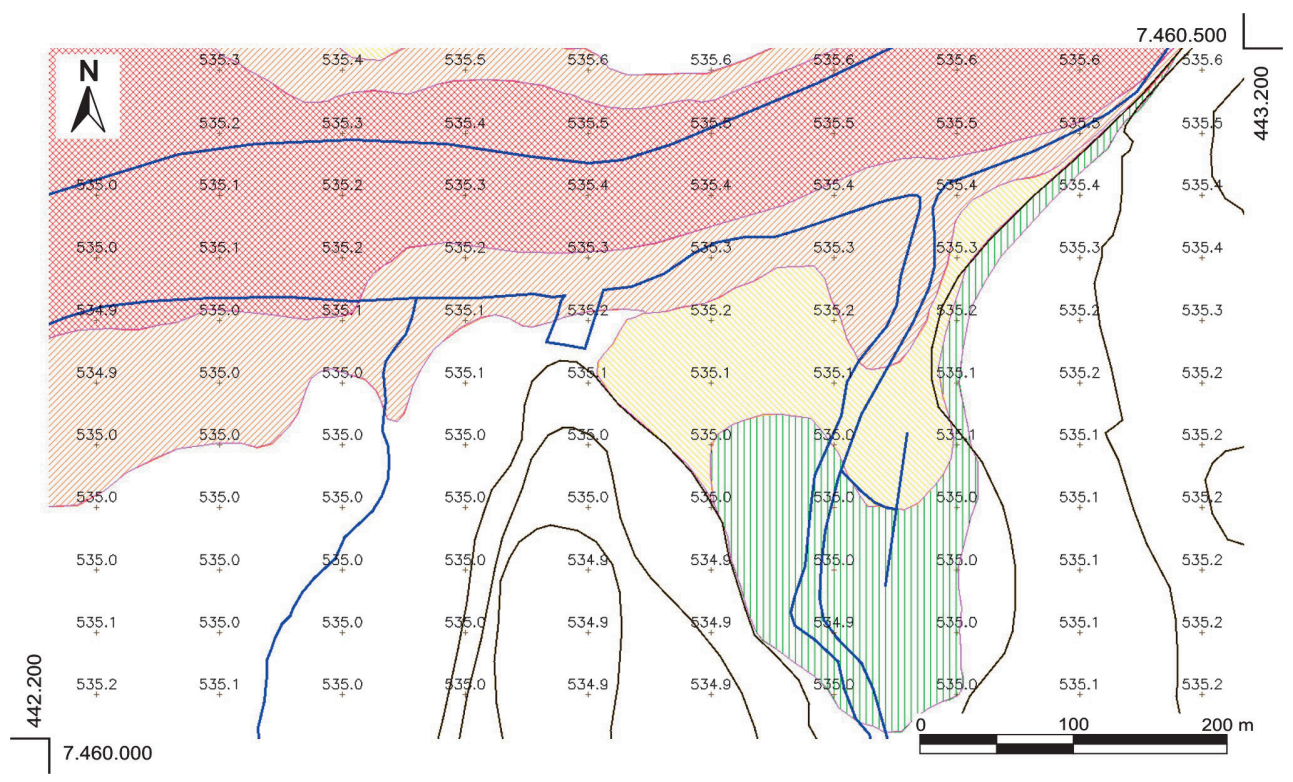

FIGURA 6 - Trecho do Rio Paraíba do Sul situado junto à desembocadura do Ribeirão do Convento Velho (Município de Tremembé). Exemplo de grade numérica interpolada das cotas de atingimento [cota altimétrica + nível da água atingido nos locais de ocorrência $(N A t)]$ em intervalos de $0,10 \mathrm{~m}$, superposta a curvas de nível com espaçamento de 1 metro. As zonas hachuradas e coloridas representam a delimitação de setores de perigo. Coordenadas UTM, Zona 23K.

das situações. A revisão dos escores numéricos implica no estabelecimento de novos limiares de classe de perigo, expressos em quatro intervalos
(Tabela 5). Isso, por sua vez, terá reflexo direto no cálculo e classificação final do grau de risco de inundação, como apresentado adiante.

TABELA 4 - Fatores de correção $(\mathrm{Fc})$ aplicados em função da recorrência dos eventos de inundação. Classificação final e escore numérico do Perigo de inundação (P).

\begin{tabular}{|c|c|c|c|c|}
\hline Critério & Perigo Preliminar $(P p)$ & Fator de Correção $\left(F_{c}\right)$ & $\begin{array}{c}\text { Escore Final } \\
(P)\end{array}$ & $\begin{array}{c}\text { Perigo Final } \\
(P)\end{array}$ \\
\hline \multirow{4}{*}{$\begin{array}{l}\text { Interpolação e interpretação de } \\
\text { imagens, sem pontos de observação } \\
\text { de campo no setor }\end{array}$} & Pp1 - Baixo & 0,500 & 0,0536 & P1 - Baixo \\
\hline & Pp2 - Moderado & 0,666 & 0,2814 & P2 - Moderado \\
\hline & Pp3 - Alto & 0,800 & 0,5634 & P3 - Alto \\
\hline & Pp4 - Muito Alto & 0,852 & 0,8520 & P4 - Muito Alto \\
\hline \multirow{4}{*}{$\begin{array}{l}\text { Presença de um ou mais pontos de } \\
\text { observação de campo no setor }\end{array}$} & Pp1 - Baixo & 1,000 & 0,1072 & P1 - Baixo \\
\hline & Pp2 - Moderado & 1,000 & 0,4226 & P2 - Moderado \\
\hline & Pp3 - Alto & 1,000 & 0,7042 & P3 - Alto \\
\hline & Pp4 - Muito Alto & 1,000 & 1,0000 & P4 - Muito Alto \\
\hline \multirow{4}{*}{$\begin{array}{l}\text { Presença de um ou mais pontos de } \\
\text { observação de campo E pelo menos } \\
\text { uma recorrência no setor }\end{array}$} & Pp1 - Baixo & 3,000 & 0,3215 & P2 - Moderado \\
\hline & Pp2 - Moderado & 1,500 & 0,6338 & P3 - Alto \\
\hline & Pp3 - Alto & 1,250 & 0,8803 & P4 - Muito Alto \\
\hline & Pp4 - Muito Alto & 1,125 & 1,1250 & P4 - Muito Alto \\
\hline \multirow{4}{*}{$\begin{array}{l}\text { Presença de um ou mais pontos de } \\
\text { observação de campo } \underline{E} \text { duas ou mais } \\
\text { recorrências no setor }\end{array}$} & Pp1 - Baixo & 3,500 & 0,3750 & P2 - Moderado \\
\hline & Pp2 - Moderado & 1,750 & 0,7395 & P4 - Muito Alto \\
\hline & Pp3 - Alto & 1,500 & 1,0563 & P4 - Muito Alto \\
\hline & Pp4 - Muito Alto & 1,500 & 1,5000 & P4 - Muito Alto \\
\hline
\end{tabular}


TABELA 5 - Classificação final do Perigo de inundação (P).

\begin{tabular}{ll}
\hline \multicolumn{1}{c}{ Perigo $(P)$} & \multicolumn{1}{c}{ Intervalo de Classe } \\
\hline P1 - Perigo Baixo & $\mathrm{P} \leq 0,1072$ \\
P2 - Perigo Moderado & $0,1072<\mathrm{P} \leq 0,4226$ \\
P3 - Perigo Alto & $0,4226<\mathrm{P} \leq 0,7042$ \\
P4 - Perigo Muito Alto & $\begin{array}{l}\mathrm{P}>0,7042 \\
\text { (máximo de 1,5000) }\end{array}$ \\
\hline
\end{tabular}

Diferentemente do Vale do Rio Paraíba do Sul, os estudos realizados no município de São José do Rio Preto mostram que em alguns trechos prevalecem os processos de enxurrada que, geralmente, potencializam a magnitude dos eventos. Tais processos estão associados à dinâmica do uso e ocupação do solo, que inclui intervenções como a canalização subterrânea dos principais córregos e a construção de grandes avenidas em fundos de vales, e às características geomorfológicas e hidrodinâmicas locais (relevo de colinas amplas, rede de drenagem com talvegues amplos).

Nestes casos específicos utilizou-se para o Perigo de Inundação um fator $(h)$ adicional de correção dos escores numéricos, constante e igual a 3,5. Este valor refere-se ao fator máximo de correção $(F c)$ apresentado na tabela 4 (equivalente à presença de um ou mais pontos de observação de campo e duas ou mais recorrências no setor), aqui adaptado para considerar o fato de que a maior energia cinética do processo de enxurrada induz um maior grau de perigo, com destaque para o aumento da velocidade de escoamento da água com grande poder destrutivo.

2.4 Análise de uso e ocupação do solo: estimativa da vulnerabilidade

A vulnerabilidade do elemento em risco consiste na sensibilidade deste elemento em resposta à ocorrência de um evento geodinâmico. A análise leva em consideração a existência de três tipos principais de elementos em risco ou potencialmente expostos aos fenômenos de inundação em áreas de ocupação predominantemente urbana: a) Edificações Residenciais, Comerciais e Serviços; b) Grandes Equipamentos (edificações de grande porte associadas a instalações industriais, minerações, galpões de armazenagem, equipamentos urbanos como hospitais, cemitérios, estações de tratamento de água e esgoto, entre outros); c) Vias (trechos isolados de rodovias e de vias principais e secundárias) (Tabela 6). Nesse contexto, como sugerido em ROSSINI-PENTEADO et al. (2007), adota-se a premissa de que a vulnerabilidade física da ocupação urbana está relacionada aos seguintes aspectos: (a) padrão construtivo das edificações (tipo de material de construção, presença de estruturas); (b) existência de infraestrutura urbana no local (arruamento, pavimentação, rede de esgoto e de águas pluviais, tubulações e canalizações do curso d'água, abastecimento de água e coleta de lixo) (Tabela 7). Ainda, os atributos relacionados ao padrão da ocupação urbana utilizados especificamente para o cálculo numérico da Vulnerabilidade (V) compreendem: (a) a tipologia construtiva; (b) o padrão construtivo; (c) a pavimentação e (d) a infraestrutura sanitária.

TABELA 6 - Principais grupos de elementos em risco ou potencialmente expostos aos fenômenos de inundação e processos correlatos característicos do uso e ocupação do solo em áreas predominantemente urbanas.

\begin{tabular}{cl}
\hline ELEMENTO EM RISCO & \multicolumn{1}{c}{ TIPO DE USO E OCUPAÇÃO DO SOLO } \\
\hline Residências, Comércio e Serviços & $\begin{array}{l}\text { Predomínio de edificações residenciais, com a presença difusa de } \\
\text { estabelecimentos comerciais e prestadores de serviços }\end{array}$ \\
\hline Grandes Equipamentos & $\begin{array}{l}\text { Edificações de grande porte associadas a instalações industriais, } \\
\text { minerações, galpões de armazenagem, equipamentos urbanos tais como } \\
\text { hospitais, cemitérios, estações de tratamento de água e esgoto, entre } \\
\text { outros }\end{array}$ \\
\hline Vias & $\begin{array}{l}\text { Trechos de vias de acesso sem a presença de nenhum outro tipo de } \\
\text { ocupação }\end{array}$ \\
\hline
\end{tabular}


TABELA 7 - Atributos relacionados ao uso e ocupação utilizados para a estimativa da Vulnerabilidade (V) e análise de risco de inundação na escala local.

\begin{tabular}{|c|c|c|}
\hline ATRIBUTO & DESCRIÇÃO & FORMA DE OBTENÇÃO \\
\hline $\begin{array}{c}\text { (TC) Tipologia } \\
\text { Construtiva }\end{array}$ & $\begin{array}{l}\text { - Expressa a resistência das edificações considerando o tipo de material de } \\
\text { construção empregado (alvenaria, madeira, tábuas/madeirite, adobe, outros) } \\
\text { - Unidade: adimensional } \\
\text { - } 3 \text { classes: boa resistência, média resistência, baixa resistência }\end{array}$ & $\begin{array}{l}\text { Análise em campo e } \\
\text { acervo fotográfico }\end{array}$ \\
\hline $\begin{array}{l}(P C) \text { Padrão } \\
\text { Construtivo }\end{array}$ & $\begin{array}{l}\text { - Expressa o padrão ou qualidade construtiva das edificações do setor (fun- } \\
\text { dações adequadas, presença de estruturas de "amarração" nas paredes, } \\
\text { método construtivo utilizado, entre outros) } \\
\text { - Unidade: adimensional } \\
\text { - } 3 \text { classes: alto, médio, baixo }\end{array}$ & $\begin{array}{l}\text { Análise em campo e } \\
\text { acervo fotográfico }\end{array}$ \\
\hline $\begin{array}{c}(P A V) \\
\text { Pavimentação }\end{array}$ & $\begin{array}{l}\text { - Caracteriza a ocupação quanto à acessibilidade, sistema de drenagem de } \\
\text { águas pluviais } \\
\text { - Unidade: porcentagem } \\
\text { - } 5 \text { classes: } 80 \text { a } 100 \% \text { (pavimentado), } 60 \text { a } 80 \%, 40 \text { a } 60 \%, 20 \text { a } 40 \%, 0 \text { a } \\
20 \%\end{array}$ & $\begin{array}{l}\text { Análise em campo e } \\
\text { acervo fotográfico }\end{array}$ \\
\hline $\begin{array}{c}\text { (INFRA) } \\
\text { Infraestrutura } \\
\text { Sanitária }\end{array}$ & $\begin{array}{l}\text { - Expressa o padrão da ocupação em termos de serviços urbanos (saneamen- } \\
\text { to básico incluindo rede de esgoto, abastecimento de água e coleta de lixo) } \\
\text { - Unidade: adimensional } \\
\text { - } 4 \text { classes: adequada, insuficiente, inadequada, ausente }\end{array}$ & $\begin{array}{l}\text { Análise em campo e } \\
\text { acervo fotográfico }\end{array}$ \\
\hline
\end{tabular}

Para a estimativa da Vulnerabilidade os atributos do uso e ocupação do solo foram divididos em classes, sendo atribuído a cada intervalo um valor numérico equivalente à mediana da respectiva classe (Tabela 8).

A modelagem da variável Vulnerabilidade (V) para o uso do tipo Edificações Residenciais/ Comércio/Serviços $\left(\mathrm{V}_{\mathrm{RCS}}\right)$ foi efetuada por meio da equação (1), na qual são adotados pesos diferenciados para cada um dos atributos considerados, obtidos por meio de ponderação arbitrada.
Dessa forma, os atributos tipologia (TC) e padrão construtivo (PC), indicadores diretos da resistência das edificações, representam $80 \%$ do escore numérico obtido, enquanto os atributos pavimentação (PAV) e infraestrutura sanitária (INFRA), que indicam de forma indireta a vulnerabilidade da ocupação, $20 \%$.

$\mathrm{V}_{\mathrm{RCS}}=0,4(\mathrm{TC})+0,4(\mathrm{PC})+0,05(\mathrm{PAV})+0,15(\mathrm{INFRA})$ Equação 1

Onde: $\mathrm{TC}=$ Tipo Construtivo; $\mathrm{PC}=$ Padrão Construtivo; $\mathrm{PAV}=$ Pavimentação; INFRA = Infraestrutura Sanitária.

TABELA 8 - Classes e notas relativas aos atributos utilizados para o cálculo da variável Vulnerabilidade $\left(\mathrm{V}_{\mathrm{RCS}}\right)$.

\begin{tabular}{|c|c|c|c|c|c|c|}
\hline ATRIBUTO & $N^{o}$ de Classes & \multicolumn{5}{|c|}{$\begin{array}{c}\text { Classes e notas ponderadas utilizadas no cálculo da variável Vulnerabilidade do } \\
\text { elemento Edificações Residenciais/Comércio/Serviços }\left(V_{R C S}\right)\end{array}$} \\
\hline \multirow{2}{*}{ (TC) Tipo Construtivo } & \multirow{2}{*}{3} & Boa Resistê & cia & Média Res & & Baixa Resistência \\
\hline & & 0,1667 & & 0,50 & & 0,8333 \\
\hline \multirow{2}{*}{$\begin{array}{l}\text { (PC) Padrão } \\
\text { Construtivo }\end{array}$} & \multirow{2}{*}{3} & Alto & & Méd & & Baixo \\
\hline & & 0,1667 & & 0,50 & & 0,8333 \\
\hline \multirow{2}{*}{ (PAV) Pavimentação } & \multirow[b]{2}{*}{ J } & $80-100 \%$ & $60-80 \%$ & $40-60 \%$ & $20-40 \%$ & $0-20 \%$ \\
\hline & & 0,1 & 0,3 & 0,5 & 0,7 & 0,9 \\
\hline \multirow{2}{*}{$\begin{array}{l}\text { (INFRA) Infraestrutura } \\
\text { Sanitária }\end{array}$} & \multirow{2}{*}{4} & Adequada & \multicolumn{2}{|c|}{ Insuficiente } & Deficiente & Inexistente \\
\hline & & 0,125 & \multicolumn{2}{|c|}{0,375} & 25 & 0,875 \\
\hline
\end{tabular}


Para definição das 4 classes de vulnerabilidade, procedeu-se à análise estatística dos resultados obtidos a partir da aplicação da equação (1) em amostra constituída de 125 setores de uso Residencial/Comércio/Serviços (em 4 municípios do Vale do Paraíba e São José do Rio Preto), com base nos valores da média e do desvio padrão (Tabela 9). Os limiares de vulnerabilidade foram estendidos e aplicados a todos os setores de perigo identificados e delimitados nos municípios estudados.

TABELA 9 - Classificação da vulnerabilidade do elemento Residências/Comércio/Serviços.

\begin{tabular}{cc}
\hline \multicolumn{1}{c}{ Vulnerabilidade $\left(V_{R C S}\right)$} & Intervalo de Classe \\
\hline V1 - Vulnerabilidade Baixa & $0,1571 \leq \mathrm{V}_{\mathrm{RCS}} \leq 0,2196$ \\
V2 - Vulnerabilidade Moderada & $0,2196<\mathrm{V}_{\mathrm{RCS}} \leq 0,3203$ \\
V3 - Vulnerabilidade Alta & $0,3203<\mathrm{V}_{\mathrm{RCS}} \leq 0,4209$ \\
V4 - Vulnerabilidade Muito Alta & $0,4209<\mathrm{V}_{\mathrm{RCS}} \leq 0,8429$ \\
\hline
\end{tabular}

Onde: $\sigma=$ desvio padrão; limiar inferior da Classe V1 = Valor mínimo obtido; limiar inferior da Classe V2 = Média dos valores obtidos; limiar inferior da Classe V3 $=$ Média $+\sigma$; limiar inferior da Classe V4 $=$ Média $+2 \sigma$; limiar superior da Classe V4 = Valor máximo obtido.

As classes de Vulnerabilidade (V) determinadas para os elementos Edificações Residenciais/ Comércio/Serviços $\left(\mathrm{V}_{\mathrm{RCS}}\right)$ também foram utilizadas como referência para o cálculo da Vulnerabilidade relativa aos demais elementos. No caso dos Grandes Equipamentos $\left(\mathrm{V}_{\mathrm{GE}}\right)$ adotou-se três índices de vulnerabilidade constantes $(k 1, k 2$ e $k 3)$, estabelecidos com base no tipo de equipamento e na distribuição estatística dos valores obtidos para
$\mathrm{V}_{\text {RCS }}$ (Tabela 10). De forma similar, adotou-se para o elemento Vias $\left(\mathrm{V}_{\text {via }}\right)$ um índice de vulnerabilidade constante $(k 4)$, equivalente à mediana da classe de menor vulnerabilidade do elemento Residências/ Comércio/Serviços $\left(\mathrm{V}_{\mathrm{RCS}}\right)$.

\subsection{Classificação dos setores de risco}

A classificação e setorização do risco é resultado da análise de uso e ocupação do solo nos setores de perigo previamente delimitados por meio de procedimentos de modelagem numérica. Assim, o Índice de Risco a Inundação $\left(R_{i m u}\right)$ foi obtido aplicando-se a equação (2) para cada tipo de elemento em risco analisado (no caso, Edificações Residenciais/Comerciais/Serviços; Grandes Equipamentos e Vias). O índice expressa numericamente o produto das variáveis Perigo $(\mathrm{P})$ e Vulnerabilidade (V), com base na equação de risco proposta por VARNES (1984).

$$
R_{\text {inu }}=\mathrm{P} * \mathrm{~V}_{\mathrm{RCS}, \mathrm{GE}, \mathrm{VIA}} \quad \text { Equação } 2
$$

Onde: $R_{i m u}=$ índice de risco inundação; $\mathrm{P}=$ índice de perigo inundação; $\mathrm{V}=$ índice de vulnerabilidade específico de cada elemento: RCS, GE ou VIA.

Os limiares das quatro classes de risco de inundação (Tabela 11) foram definidos a partir da análise estatística dos resultados obtidos pela aplicação da equação (2). Para isso utilizou-se uma amostra de referência constituída por 164 setores distribuídos em 4 municípios do Vale do Paraíba e em São José do Rio Preto, incluindo: 124 setores de uso Residencial/Comercial/Serviços, 28 setores

TABELA 10 - Cálculo da variável Vulnerabilidade dos diferentes elementos em relação aos eventos de inundação.

\begin{tabular}{ll}
\hline \multicolumn{1}{c}{ ELEMENTO EM RISCO } & \multicolumn{1}{c}{ CÁLCULO DA VULNERABILIDADE $(V)$} \\
\hline $\begin{array}{l}\text { RESIDENNCIAS/COMÉRCIO/ } \\
\text { SERVIÇOS }\end{array}$ & $\mathrm{V}_{\mathrm{RCS}}=0,4(\mathrm{TC})+0,4(\mathrm{PC})+0,05(\mathrm{PAV})+0,15(\mathrm{INFRA})$ \\
\hline & $\mathrm{V}_{\mathrm{GE}}$ (Escolas, Hospitais, Igrejas, e similares $)=\mathrm{k} 1=0,3706$ \\
GRANDES EQUIPAMENTOS & $\mathrm{V}_{\mathrm{GE}}$ (Indústrias e similares $)=\mathrm{k} 2=0,2196$ \\
& $\mathrm{~V}_{\mathrm{GE}}$ (Minerações, Grandes pátios, Parques, e similares $)=\mathrm{k} 3=0,1571$ \\
\hline VIAS & $\mathrm{V}_{\mathrm{Via}}=\mathrm{k} 4=0,1884$ \\
\hline
\end{tabular}

Onde: $\mathrm{TC}=$ tipo construtivo; $\mathrm{PC}=$ padrão construtivo; $\mathrm{PAV}=$ pavimentação; INFRA = infra-estrutura; $\mathrm{k} 1=$ ponto médio (mediana) da classe de vulnerabilidade alta (V3) do elemento Residências, Comércios e Serviços; k2 = limiar inferior da classe de vulnerabilidade moderada (V2) do elemento Residências, Comércios e Serviços; k3 = limiar inferior da classe de vulnerabilidade baixa (V1) do elemento Residências, Comércios e Serviços; k4 = ponto médio (mediana) da classe de vulnerabilidade baixa (V1) do elemento Residências, Comércios e Serviços. 
de Grandes equipamentos e 12 setores compostos exclusivamente por Vias. Os limiares basearam-se nos valores da média e do desvio padrão relativos ao total de setores da amostra de referência, os quais foram então estendidos e aplicados aos demais municípios estudados.

TABELA 11 - Classificação do Risco de Inundação $\left(R_{i n u}\right)$ e respectivos intervalos numéricos de classe.

\begin{tabular}{ll}
\hline \multicolumn{1}{c}{ Risco $\left(R_{\text {inu }}\right)$} & \multicolumn{1}{c}{ Intervalo de Classe } \\
\hline R1 - Risco Baixo & $0,00842 \leq \mathrm{R}_{\text {inu }} \leq 0,08595$ \\
R2 - Risco Moderado & $0,08595<\mathrm{R}_{\text {inu }} \leq 0,20919$ \\
R3 - Risco Alto & $0,20919<\mathrm{R}_{\text {inu }} \leq 0,33242$ \\
R4 - Risco Muito Alto & $0,33242<\mathrm{R}_{\text {inu }} \leq 0,90606$ \\
\hline
\end{tabular}

Onde: $\sigma=$ desvio padrão; limiar inferior da Classe R1 = Valor mínimo obtido; limiar inferior da Classe R2 = Média dos valores obtidos; limiar inferior da Classe R3 $=$ Média $+\sigma$; limiar inferior da Classe R4 = Média $+2 \sigma$; limiar superior da Classe R4 = Valor máximo obtido.
As características gerais dos setores de risco (frequência e magnitude dos eventos), segundo a classificação de Índice de Risco a Inundação $\left(R_{i m u}\right)$, são apresentadas na Tabela 12.

\subsection{Estimativa de dano potencial}

O potencial de dano aos elementos em risco (pessoas, bens materiais e atividades econômicas) está associado aos setores de risco de inundação. De acordo com DIAS et al. (2014), a bibliografia atual sobre a determinação dos danos (diretos e indiretos) causados por eventos de cheias e inundações refere-se a: i) relação da velocidade e profundidade da água necessária para uma pessoa ser arrastada; ii) dano causado em veículos automotores; iii) danos causados em infraestruturas rodoferroviárias, em áreas agrícolas e de pastagens; iv) danos causados em edificações com diferentes níveis de desagregação; v) danos causados a edificações de indústrias e comércio e respectivas atividades econômicas, entre outros.

TABELA 12 - Características gerais da frequência e magnitude dos eventos de inundação e processos correlatos nos setores de risco mapeados, segundo classificação realizada por meio do Índice de Risco a Inundação $\left(R_{\text {inu }}\right)$.

\begin{tabular}{|c|c|c|}
\hline \multirow{4}{*}{ 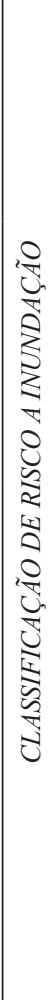 } & $\begin{array}{c}R 1 \\
B A I X O\end{array}$ & $\begin{array}{l}\text { - } R_{i n u} \leq 0,08595 \\
\text { - O setor apresenta algumas condições potenciais para o desenvolvimento de processos de inundação } \\
\text { - Os eventos de inundação/enchente são pouco frequentes, em geral, sendo registrada a ocorrência de } \\
\text { pelo menos } 1 \text { (um) evento de inundação/enchente, com nível de atingimento de até } 0,40 \text { m nos últimos } \\
10 \text { anos }\end{array}$ \\
\hline & $\begin{array}{c}R 2 \\
M O D E R A D O\end{array}$ & $\begin{array}{l}\text { - } 0,08595<R_{i n u} \leq 0,20919 \\
\text { - O setor apresenta condições potenciais para o desenvolvimento de processos de inundação: localização } \\
\text { em áreas de vale e de baixada (várzeas) ou proximidade das edificações ou vias em relação aos cursos } \\
\text { de água. Em alguns casos, risco potencializado pela vulnerabilidade das edificações } \\
\text { - Os eventos de inundação/enchente são moderadamente frequentes, sendo registrada a ocorrência de } 1 \\
\text { (um) ou mais eventos, com nível de atingimento de até } 0,80 \mathrm{~m} \text {, nos últimos } 10 \text { anos }\end{array}$ \\
\hline & $\begin{array}{c}R 3 \\
A L T O\end{array}$ & $\begin{array}{l}\text { - } 0,20919<R_{\text {imu }} \leq 0,33242 \\
\text { - As condições verificadas no setor são favoráveis ao desenvolvimento de processos de inundação: } \\
\text { localização em áreas de vale e de baixada (várzeas) e proximidade das edificações ou vias em relação } \\
\text { aos cursos de água. Em geral, risco potencializado pela vulnerabilidade das edificações } \\
\text { - Os eventos de inundação/enchente são frequentes, sendo registrada a ocorrência de } 2 \text { (dois) ou mais } \\
\text { eventos significativos, com nível de atingimento de } 0,80 \text { até } 1,20 \mathrm{~m} \text {, nos últimos } 10 \text { anos }\end{array}$ \\
\hline & $\begin{array}{c}R 4 \\
\text { MUITO ALTO }\end{array}$ & $\begin{array}{l}\text { - } 0,33242<R_{\text {inu }} \leq 0,90606 \\
\text { - As condições verificadas no setor são muito favoráveis ao desenvolvimento de processos de inundação: } \\
\text { localização em áreas de vale e de baixada (várzeas) e grande proximidade das edificações ou vias em } \\
\text { relação aos cursos de água. Em geral, risco potencializado pela vulnerabilidade das edificações } \\
\text { - A frequência dos eventos de inundação/enchente é elevada, sendo registrada a ocorrência de } 2 \text { (dois) ou } \\
\text { mais eventos significativos, nos últimos } 10 \text { anos,em geral, com nível de atingimento superiores a } 1,20 \mathrm{~m}\end{array}$ \\
\hline
\end{tabular}


No presente estudo, seguindo as equações formuladas por VARNES (1984), onde o risco é uma função apenas do perigo $(\mathrm{P})$ e da vulnerabilidade dos elementos expostos aos fenômenos (V), o dano potencial (D) é tratado como um parâmetro qualificador do grau de risco atribuído ao setor. Tal aspecto difere do sugerido por TOMINAGA et al. (2004, 2008) e TOMINAGA (2009), onde o dano é uma variável componente da equação de risco $R$ $=[\mathrm{P} \times(\mathrm{V} \times \mathrm{D})]$, e por $\operatorname{SOUZA}(2004,2009)$, para o caso específico de inundações, onde $\mathrm{R}=(\mathrm{P} \times \mathrm{D})$. A modelagem semiquantitativa realizada no presente estudo sugere que os escores numéricos são extremamente influenciados pela quantificação do dano e por sua inclusão na equação de risco, alterando sobremaneira a atribuição do grau de risco, e, consequentemente, a classificação dos setores. Esta aparente distorção se dá, primeiramente, pela dificuldade prática em aferir e quantificar numericamente - numa grandeza escalar de zero até um (0 a 1) - os elementos em risco que são díspares, tais como: o número de moradores, as edificações de diferentes portes e os padrões construtivos. Dessa forma, a estimativa de dano potencial procura avaliar de forma indireta o número de pessoas expostas ao risco de inundação e os prejuízos materiais e econômicos nos setores analisados, preservando o grau de risco atribuído ao setor (muito alto, alto, moderado, baixo) com base na avaliação do perigo e na vulnerabilidade dos elementos expostos. Para tal, foram considerados os seguintes atributos: (a) o número de moradias existentes ( $\left.\mathrm{N}^{\mathrm{o}} \mathrm{EDIF}\right)$; (b) o número de Grandes Equipamentos (EQUIP); (c) a extensão de Vias (TV) expressa em metros. O número de moradias existentes nos setores de risco pode ser utilizado de forma combinada aos dados censitários ou, alternativamente, arbitrando-se um número fixo de moradores por domicílio para estimar o número de pessoas em situações de risco nos setores e, por conseguinte, nos núcleos habitacionais estudados.

\section{RESULTADOS}

A modelagem e os mapas de perigo e de risco produzidos permitiram a identificação de 85 áreas sujeitas à ocorrência de eventos de inundações, distribuídas por 7 municípios no Vale do Rio Paraíba do Sul e 11 áreas no município de São José do Rio Preto. Juntas, estas 96 áreas totalizaram 380 setores de perigo e 375 setores de risco de inundação. No Vale do Paraíba foram identificados 56 setores de risco muito alto e alto (16\%) abrangendo 760 moradias, 96 setores de risco moderado (28\%) com 1246 moradias e 190 setores de risco baixo (56\%) com
3251 moradias, que totalizam 5257 moradias e 34 grandes equipamentos em risco (escolas, parques, espaços poliesportivos, galpões industriais-comerciais, indústrias e minerações), além de diversos trechos de vias pavimentadas e não pavimentadas que superam 20 quilômetros lineares. Em São José do Rio Preto foram identificados 2 setores de risco alto $(6 \%)$ em áreas predominantemente comerciais, 9 setores de risco moderado (27\%) com 2 moradias e 22 setores de risco baixo (67\%) com 102 moradias, que totalizam 104 moradias, 5 grandes equipamentos (Clube; Biblioteca Municipal; Companhia de Abastecimento de Água; Rodoviária e Estação de Trem), 95 estabelecimentos comerciais e, aproximadamente, $10 \mathrm{~km}$ de vias pavimentadas em risco. Dentre os 33 setores de risco de inundação identificados em São José do Rio Preto, 3 deles estão associados a processos de enxurrada; 2 setores de risco alto referem-se a trechos canalizados do Córrego Borá e do Córrego Canela situados ao longo de importantes avenidas do município que cortam a porção central da mancha urbana, com alto índice de impermeabilização. A distribuição percentual dos 375 setores de risco de inundação mapeados e das moradias abrangidas nos sete municípios do Vale do Paraíba e em São José do Rio Preto é ilustrada na figura 7.
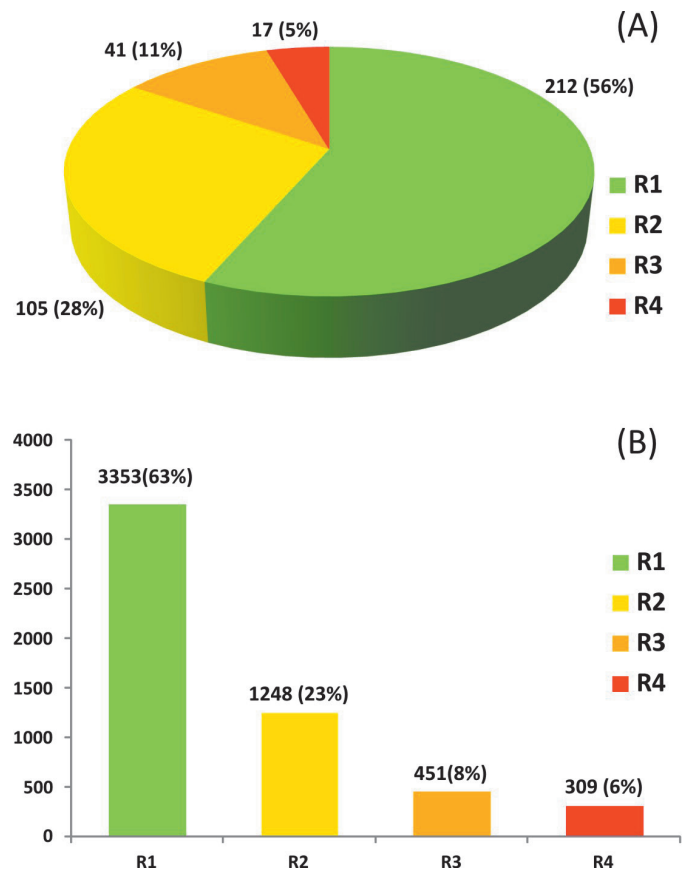

FIGURA 7 - (A) Distribuição dos setores de risco de inundação mapeados (total de 375), segundo as classes de risco. (B) Distribuição das moradias presentes nos setores de risco mapeados segundo classificação de risco (total de 5361 moradias referentes a São José do Rio Preto e aos sete municípios estudados no Vale do Paraíba). 
Na tabela 13 são apresentados resultados da modelagem numérica de risco para os setores de inundação, utilizando exemplos dos municípios de São José do Rio Preto (no noroeste do Estado) e de Guaratinguetá (no Vale do Rio Paraíba do Sul). Nestes exemplos é possível visualizar a relação entre as classes de perigo e de vulnerabilidade e a classificação final de risco de inundação. As figuras
8A e $8 \mathrm{~B}$ são exemplos da setorização e respectiva classificação de perigo e de risco em área do município de Guaratinguetá, enquanto as figuras 9 e 10 apresentam exemplos do município de São José do Rio Preto, com destaque para o setor de Risco Alto, onde foram observados processos de enxurrada. Os setores referidos na tabela 13 correspondem aos exemplos apresentados nas figuras 8,9 e 10 .

TABELA 13 - Resultados da modelagem numérica de risco de inundação em 3 áreas estudadas (São José do Rio Preto - Áreas 9 e 14, referentes ao Córrego Borá e ao Córrego do Macaco, respectivamente, e Guaratinguetá - A22, referente ao Bairro Jardim Esperança, situado junto à margem esquerda do Rio Paraíba do Sul). Nomenclatura codificada das áreas e dos setores de risco, escores numéricos de perigo, vulnerabilidade e risco e respectivas classificações. Também são apresentados os elementos em risco e a estimativa de danos potenciais para cada um dos setores (Fonte: IG 2012a, b).

\begin{tabular}{|c|c|c|c|c|c|c|c|c|c|c|}
\hline \multirow{2}{*}{\multicolumn{2}{|c|}{$\begin{array}{c}\text { Município/ } \\
\text { Nome da área }\end{array}$}} & \multirow{3}{*}{\begin{tabular}{|l}
$\begin{array}{l}\text { Área/Setor/ } \\
\text { Grau }\end{array}$ \\
$\begin{array}{c}\text { A9/S1/R1 } \\
\text { inu }\end{array}$ \\
\end{tabular}} & \multicolumn{2}{|c|}{ PERIGO } & \multicolumn{2}{|c|}{ VULNERABILIDADE } & \multicolumn{2}{|c|}{ RISCO } & \multicolumn{2}{|c|}{$D A N O$} \\
\hline & & & Escore & Classe & Escore & Classe & Escore & Classe & Elemento em & Quantificação \\
\hline \multirow{8}{*}{ 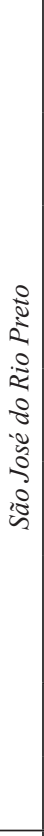 } & \multirow{6}{*}{$\begin{array}{c}\text { A9 - } \\
\text { Córrego } \\
\text { Borá }\end{array}$} & & 0,3750 & $\mathrm{P} 2$ & 0,1571 & V1 & 0,0589 & R1 & $\begin{array}{l}\text { moradias / } \\
\text { estab. } \\
\text { comerciais }\end{array}$ & $7 / 7$ \\
\hline & & $\begin{array}{c}\mathrm{A} 9 / \mathrm{S} 2 / \mathrm{R} 1 \\
\text { inu }\end{array}$ & 0,7395 & P4 & 0,1571 & V1 & 0,1162 & R1 & $\begin{array}{c}\text { estab. } \\
\text { comerciais }\end{array}$ & 1 \\
\hline & & $\begin{array}{c}\text { A9/S3/R3 } \\
\text { inu }\end{array}$ & 2,5883 & P4 & 0,1571 & V1 & 0,4066 & R3 & vias & $\begin{array}{c}\text { Toda } \\
\text { extensão da } \\
\text { Av. Bady } \\
\text { Bassit }\end{array}$ \\
\hline & & $\begin{array}{l}\text { A9/S4/R1 } \\
\text { inu }\end{array}$ & 0,3750 & P2 & 0,1571 & V1 & 0,0589 & R1 & $\begin{array}{c}\text { estab. } \\
\text { comerciais }\end{array}$ & 14 \\
\hline & & $\begin{array}{c}\mathrm{A} 9 / \mathrm{S} 5 / \mathrm{R} 1 \\
\text { inu }\end{array}$ & 0,7395 & P4 & 0,1571 & V1 & 0,1162 & $\mathrm{R} 1$ & $\begin{array}{c}\text { estab. } \\
\text { comerciais }\end{array}$ & 2 \\
\hline & & $\begin{array}{c}\text { A9/S6/R2 } \\
\text { inu }\end{array}$ & 1,5000 & P4 & 0,1571 & V1 & 0,2357 & R2 & $\begin{array}{c}\text { estab. } \\
\text { comerciais / } \\
\text { terminal }\end{array}$ & $2 / 1$ \\
\hline & \multirow{2}{*}{$\begin{array}{c}\text { A14 - } \\
\text { Córrego } \\
\text { do Ma- } \\
\text { caco }\end{array}$} & $\begin{array}{c}\mathrm{A} 14 / \mathrm{S} 1 / \mathrm{R} 1 \\
\text { inu }\end{array}$ & 0,0536 & P1 & 0,3679 & V2 & 0,0197 & R1 & moradias & 4 \\
\hline & & $\begin{array}{c}\mathrm{A} 14 / \mathrm{S} 2 / \mathrm{R} 1 \\
\text { inu }\end{array}$ & 0,2814 & P2 & 0,3679 & V2 & 0,1035 & R1 & moradias & 13 \\
\hline \multirow{7}{*}{ 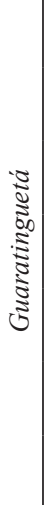 } & \multirow{7}{*}{$\begin{array}{l}\text { Área } 22 \text { - } \\
\text { Jd. Espe- } \\
\quad \text { rança }\end{array}$} & $\begin{array}{c}\mathrm{A} 22 / \mathrm{S} 1 / \mathrm{R} 4 \\
\text { inu }\end{array}$ & 1,5000 & $\mathrm{P} 4$ & 0,5013 & V3 & 0,7519 & R4 & moradias & 16 \\
\hline & & $\begin{array}{c}\mathrm{A} 22 / \mathrm{S} 2 / \mathrm{R} 3 \\
\text { inu }\end{array}$ & 0,9683 & P4 & 0,5013 & V3 & 0,4854 & R3 & moradias & 21 \\
\hline & & $\begin{array}{c}\mathrm{A} 22 / \mathrm{S} 3 / \mathrm{R} 3 \\
\text { inu }\end{array}$ & 0,7395 & P4 & 0,5013 & V3 & 0,3707 & R3 & moradias & 26 \\
\hline & & $\begin{array}{c}\mathrm{A} 22 / \mathrm{S} 4 / \mathrm{R} 2 \\
\text { inu }\end{array}$ & 0,3750 & P2 & 0,5013 & V3 & 0,1880 & $\mathrm{R} 2$ & moradias & 105 \\
\hline & & $\begin{array}{c}\text { A22/S5/R1 } \\
\text { inu }\end{array}$ & 0,3750 & P2 & 0,3679 & V2 & 0,1380 & R1 & moradias & 183 \\
\hline & & $\begin{array}{c}\text { A22/S6/R2 } \\
\text { inu }\end{array}$ & 0,7395 & P4 & 0,3679 & V2 & 0,2720 & R2 & moradias & 48 \\
\hline & & $\begin{array}{c}\mathrm{A} 22 / \mathrm{S} 7 / \mathrm{R} 3 \\
\text { inu }\end{array}$ & 0,9683 & P4 & 0,3679 & V2 & 0,3563 & R3 & moradias & 9 \\
\hline
\end{tabular}




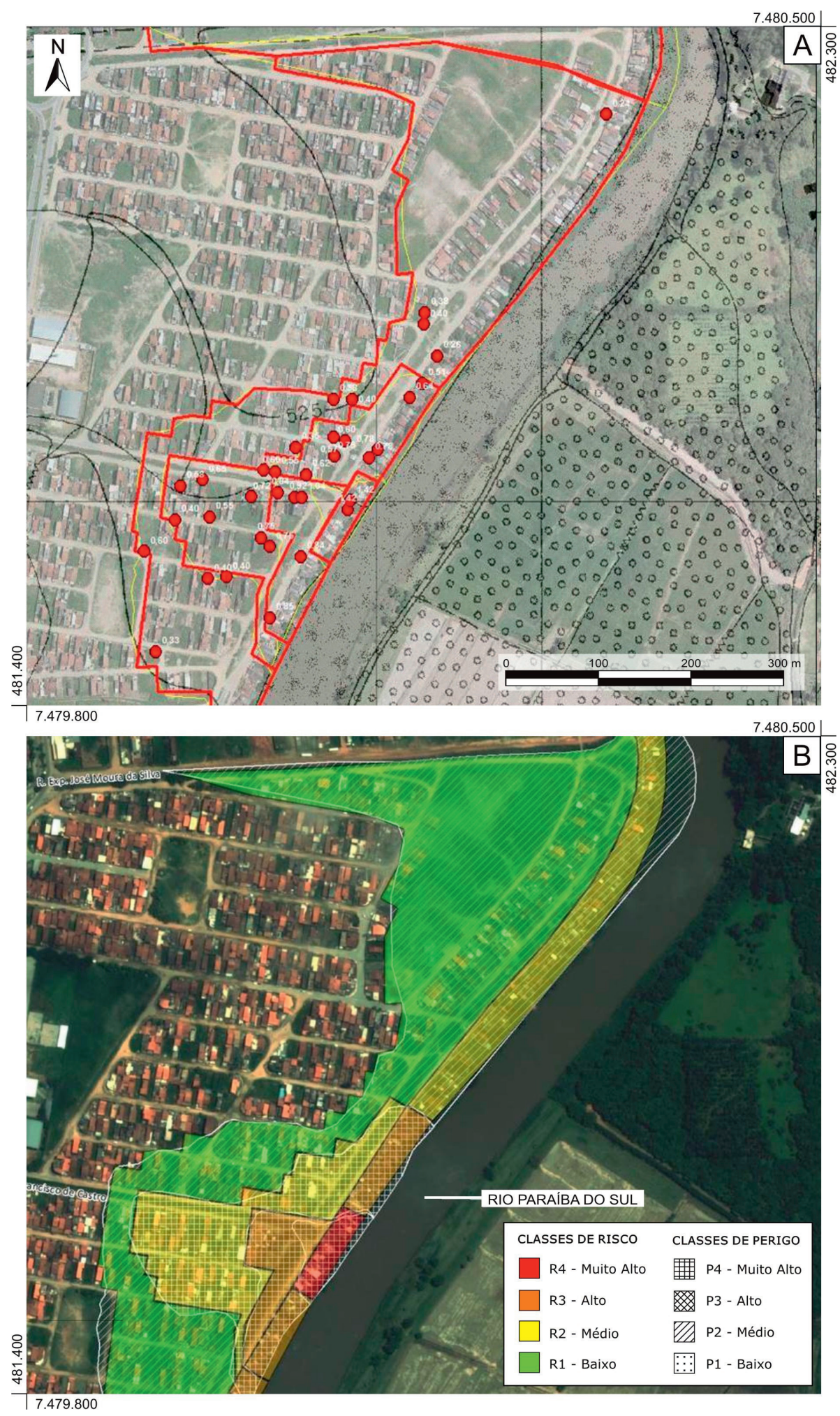

FIGURA 8 - (A) Locais onde o NAt foi medido a partir de marcas d'água observadas nos trabalhos de campo (pontos vermelhos) e a delimitação de setores de perigo preliminar (linhas vermelhas) em trecho da margem esquerda do Rio Paraíba do Sul, Município de Guaratinguetá. Imagem (ortofoto) superposta por base cartográfica com curvas de nível (IGC, 1:10.000). (B) Resultado da classificação dos setores de perigo (hachura) e de risco (cores) delimitados sobre ortofoto. Para detalhe, vide tabela 13. Coordenadas UTM, Zona 23K. 


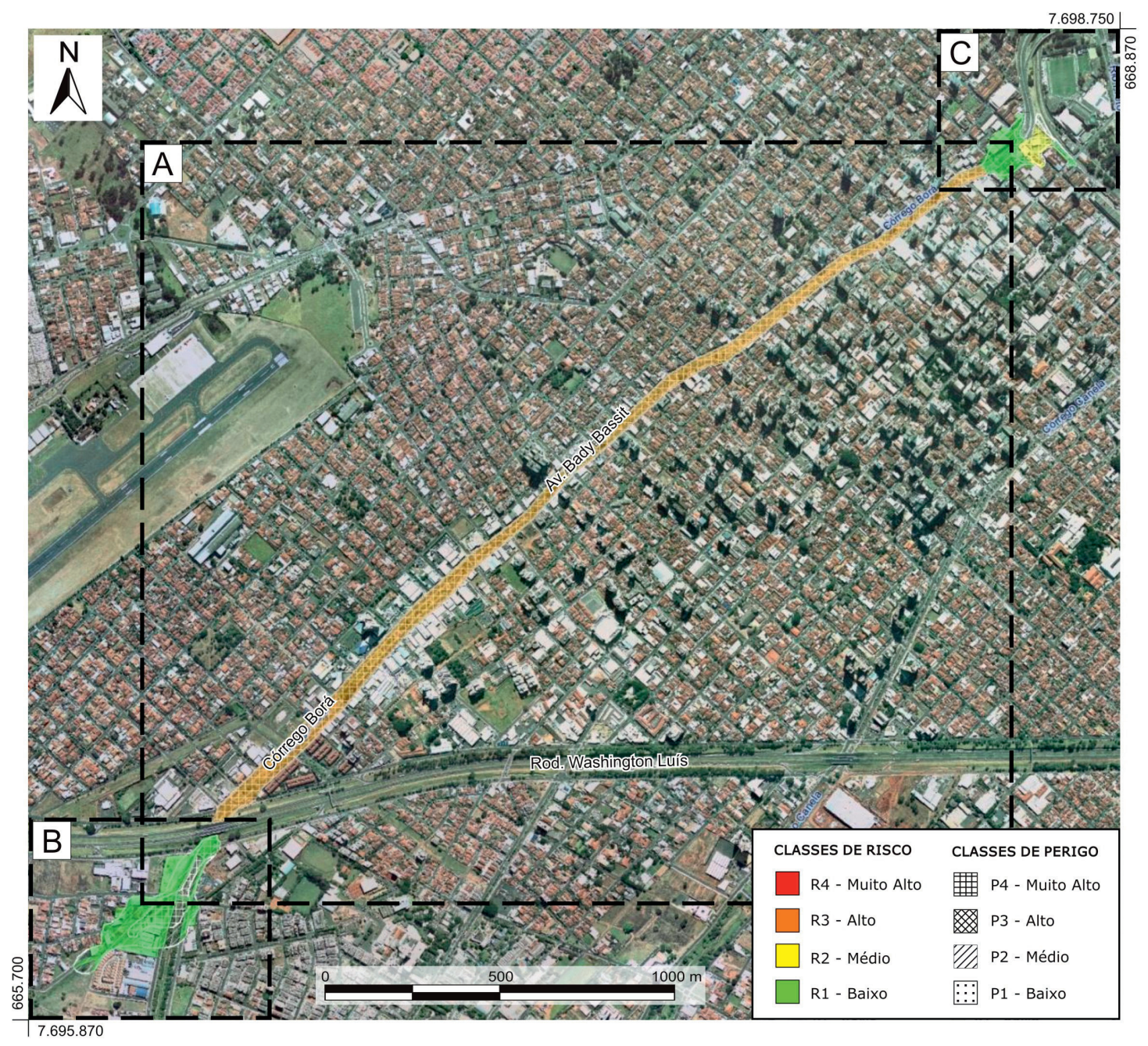

FIGURA 9 - Setores de perigo e risco situados ao longo do Córrego Borá, município de São José do Rio Preto, e respectivas classificações, identificados em imagem (ortofoto) da área urbana. Nesta área foram identificadas três dinâmicas distintas com relação aos fenômenos estudados. Trecho A: Trecho de córrego com canalização fechada (sob a Avenida Bady Bassit), sujeito à ocorrência de enxurradas, R3 - Risco Alto. Trecho B: situado a montante de drenagem canalizada e sujeito a ocorrência de inundação em decorrência de intervenções antrópicas no local e a jusante (canalização fechada), R1 - Risco Baixo. Trecho C: situado junto à desembocadura do Córrego Borá, margem esquerda do Rio Preto, sujeito a ocorrência de inundações causadas pelas águas do próprio córrego por meio da canalização e do processo de enxurrada; por vezes, a situação se agrava devido à cheia do Rio Preto, com a formação local de remanso, R2 e R1 - riscos moderado (médio) e baixo. Vide tabela 13 para detalhes. Coordenadas UTM, Zona 22K.

A tabela 14 apresenta, de forma resumida, um conjunto de recomendações de cunho geral e as respectivas medidas estruturais e não estruturais aplicáveis aos setores de risco identificados nos municípios estudados. Elas variam de acordo com as observações efetuadas e características de cada setor mapeado, compondo um dos principais produtos do mapeamento de risco.

\section{DISCUSSÃO E CONCLUSÕES}

Segundo JHA et al. (2012), o uso de mapas para a comunicação de perigo e risco de inundações é uma ferramenta valiosa para a tomada de decisão e a gestão urbana. Um dos principais objetivos do mapeamento de risco executado em escala local, no caso do Brasil e do Estado de São 


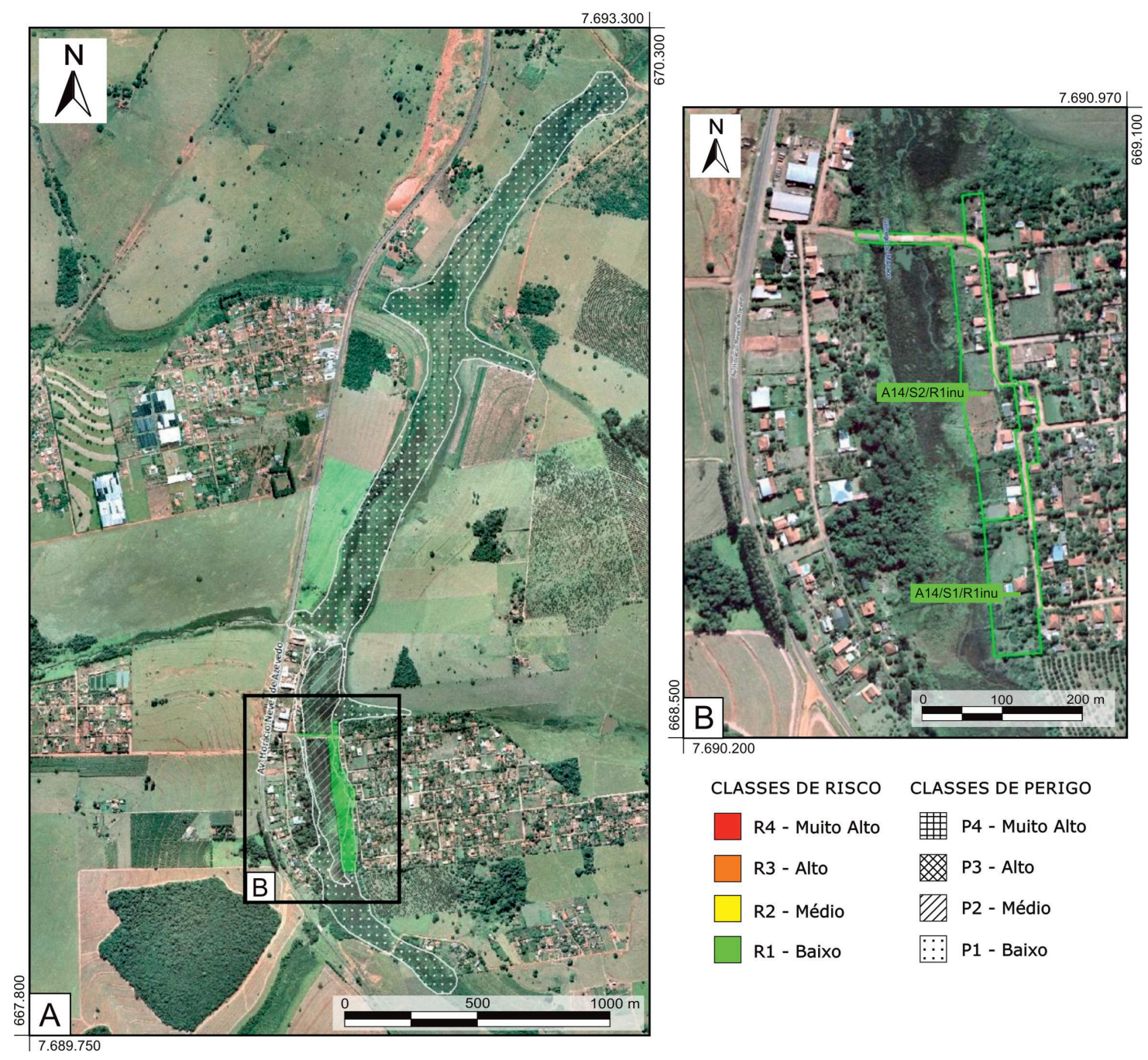

FIGURA 10 - (A) Imagem (ortofoto) de núcleo residencial situado junto à planície de inundação do Córrego do Macaco, ao sul da área urbana principal do município de São José do Rio Preto, com a delimitação e classificação de dois setores de perigo (P2 e P3), que se prolongam por trechos ainda não ocupados, e de dois setores de risco de inundação (ambos R1). (B) Detalhe da delimitação dos setores de risco resultantes da análise de perigo e de vulnerabilidade da ocupação existente. Vide texto e tabela 13 para detalhes. Coordenadas UTM, Zona 22K.

Paulo, é fornecer subsídios técnicos ao Poder Público, em particular, à esfera administrativa municipal, na forma de recomendações destinadas a remediar, mitigar e prevenir as situações de risco encontradas. O método proposto, voltado ao estudo dos fenômenos de inundação e processos correlatos (enchentes, enxurradas, alagamentos) teve um caráter empírico. Foi efetuado na escala 1:3.000 explorando o uso de bases de dados e ferramentas geotecnológicas de livre acesso disponíveis na Internet para coleta e espacialização de dados e procedimentos numérico-quantitativos para modelagem e determinação de graus de perigo e de risco. O trabalho apresenta algumas particularidades e contribuições metodológicas que merecem destaque, brevemente discutidas a seguir.

É oportuno destacar mais uma vez que o método foi desenvolvido levando em consideração a qualidade e a disponibilidade de dados e informações, e, em especial, a demanda para se implementar uma política pública de gestão de desastres no Estado de São Paulo. A inexistência de bases cartográficas submétricas que permitissem a modelagem detalhada do terreno é outro aspecto que foi 
TABELA 14 - Sumário das recomendações gerais para os setores de risco.

\begin{tabular}{|c|c|}
\hline Medidas Estruturais & Medidas Não Estruturais \\
\hline $\begin{array}{l}\text { - Proteção superficial das margens (recuperação e proteção } \\
\text { vegetal) } \\
\text { - Proteção superficial das margens (intervenções de pequeno } \\
\text { porte: gabião, manta, impermeabilização asfáltica, solo- } \\
\text { cimento, argamassa, tela, ou outros métodos) } \\
\text { - Controle da drenagem superficial e da erosão do solo } \\
\text { (melhoria na infiltração, disciplinamento das águas, } \\
\text { estabilização de taludes) } \\
\text { - Intervenções e obras para redução e controle da vazão, } \\
\text { incluindo construção de bacias de amortecimento, diques e } \\
\text { poulders, instalação de bombas para esgotamento/retirada } \\
\text { de águas (demandam estudos hidrológicos e projetos } \\
\text { específicos) } \\
\text { - Intervenções e obras para aumento da vazão, incluindo } \\
\text { recomposição do canal ou modificações na forma e trajeto } \\
\text { (demandam estudos hidrológicos e projetos específicos) } \\
\text { - Gerenciamento hídrico da microbacia de acordo com } \\
\text { estudos hidrológicos, projetos e obras específicos }\end{array}$ & $\begin{array}{l}\text { - Implantação de sistemas de previsão e alerta de cheias } \\
\text { - Implantação de Planos de Contingência e Planos } \\
\text { Preventivos de Defesa Civil (PPDC) } \\
\text { - Remoção temporária de moradores em períodos chuvosos } \\
\text { de acordo com os procedimentos de operação de Planos } \\
\text { Preventivos de Defesa Civil } \\
\text { - Remoção definitiva de edificações e monitoramento dos } \\
\text { terrenos de forma a evitar o surgimento de novas ocupações } \\
\text { (em áreas de perigo ou áreas em que já houve remoção } \\
\text { definitiva) } \\
\text { - Realização de inspeções regulares das condições } \\
\text { da canalização da drenagem quanto a obstruções e } \\
\text { assoreamento } \\
\text { - Serviços de limpeza e recuperação do canal e margens } \\
\text { - Desassoreamento e a manutenção das valas de drenagem } \\
\text { paralelas à infraestrutura linear (vias, ferrovias etc) }\end{array}$ \\
\hline
\end{tabular}

considerado no desenvolvimento e aplicação desse método, assim como sua relativa simplicidade e replicabilidade pelo poder público local (levando-se em conta a necessidade de constante atualização dos mapeamentos de risco). Com essas premissas, o método diferencia-se dos métodos geomorfológicos, que exploram as formas do terreno e depósitos sedimentares para estimar a frequência e a magnitude dos eventos de cheia e, em parte, dos métodos hidráulico-hidrológicos que utilizam parâmetros como a velocidade do fluxo hidrodinâmico, a vazão máxima e o tempo de retorno dos fenômenos que, em geral, envolvem a coleta de dados e o monitoramento por médio-longo prazo.

Dentre as contribuições assinala-se também a análise diferenciada do perigo $(\mathrm{P})$ e do risco (R) de inundação em áreas urbanas com a obtenção de índices ou escores numéricos para cada uma destas variáveis, com potencial de aplicação tanto para o planejamento territorial quanto para o gerenciamento das situações de risco já existentes. Nesse contexto, o mapa de perigos e respectivos escores numéricos antecipa a criação de potenciais áreas de risco, caso locais sujeitos a eventos venham a ser ocupados inadequadamente. Dessa forma, ele serve aos propósitos do planejamento urbano e à formulação de políticas públicas de uso e ocupação do solo (habitação, desenvolvimento e atividades econômicas), como apontado em MERZ et al. (2007) e JHA et al. (2012). Todavia, cabe também assinalar as possíveis vantagens e desvantagens da presente abordagem, que, por questões operacionais, estende-se apenas às áreas adjacentes à atual ocupação do terreno. Pode-se argumentar, por exemplo, que a coleta de dados, em particular as marcas do nível atingido pela inundação em locais de ocupação relevante, restrita a períodos mais recentes, limita a espacialidade e, por conseguinte, a aplicabilidade do método. Por outro lado, as áreas urbanas consolidadas e em consolidação, ou com potencial de expansão, constituem o foco principal do trabalho de mapeamento de risco voltado à ação do Poder Público. Como apontado em ESPANHA (2008), os métodos históricos são considerados subjetivos e parciais no que se refere aos limites cartográficos das áreas inundáveis, por estarem restritos aos locais onde os eventos de inundação foram documentados. Entretanto, estes métodos partem de uma realidade irrefutável: fundamentam-se em elementos físicos reconhecíveis no terreno e na documentação factual existente, que são evidências empíricas e não artifícios estatísticos ou matemáticos.

A suposta objetividade dos métodos hidráulico-hidrológicos também tem sido questionada, pois que, não raro, utilizam informações escassas, cujos registros, são por vezes, incompletos ou descontínuos (por exemplo, dados pluviométricos e de vazão, parâmetros de infiltração) e assumem hipóteses que muitas vezes não ocorrem num sistema natural. Tais aspectos são apontados, por exemplo, em PINHEIRO (2003) e MADSEN et al. (2013), 
no que se refere à estimativa do tempo de retorno, magnitude e frequência dos fenômenos de inundação, particularmente quando os dados de vazões são insuficientes e se faz necessário inferir a distribuição de vazões, numa bacia ou trecho de bacia, a partir da distribuição da precipitação pluviométrica e da modelagem estatística de dados de chuva $v s$. escoamento superficial. Boa parte dos métodos voltados à análise da frequência dos eventos de inundação e estimativa do tempo de retorno (e respectiva magnitude), incluindo métodos geomorfológicos, assume a hipótese de uma distribuição contínua de probabilidade para inferir valores do fluxo hidrodinâmico (velocidade, vazão etc) com base em eventos anteriores, visando extrapolar esses valores de fluxo em séries temporais de 50, 100 e 1000 anos. BEVEN \& CARLING (1989) alertam para o fato de que as limitações espaciais e temporais na disponibilidade de dados sobre o fluxo hidrodinâmico comprometem a assunção de tal hipótese, além de que os valores registrados em grandes cheias são tratados como anomalias (outliers) na análise estatística, o que torna muito difícil a estimativa do tempo de retorno de evento de igual magnitude.

O presente estudo adota o número de ocorrências num intervalo determinado de tempo (no caso, 10 anos) em substituição à estimativa de frequência e do tempo de retorno dos fenômenos de inundação, parâmetros cuja determinação em muitos casos não é possível em bacias urbanas por razões diversas, que vão desde alterações das feições geomorfológicas e sequências sedimentares (no caso de aplicação de métodos geomorfológicos), à carência de dados disponíveis e à necessidade de extensa coleta e monitoramento em longa série histórica (no caso de métodos hidráulico-hidrológicos). A escolha de um intervalo fixo de 10 anos tem viés empírico, adequado à abordagem adotada (método histórico), em vista da existência de dados de notícias de jornal e registros das defesas civis (municipal e estadual).

O intervalo de 10 anos é comumente aplicado em estudos de drenagem urbana e no cálculo de vazões de pico para dimensionamento de obras civis e estudos hidrológicos em áreas urbanas densamente construídas, com particular ênfase às chuvas mais frequentes. Assim como apresentado em TUCCI (2005), o intervalo de tempo de 10 anos significa que, em média, a cheia ou evento chuvoso de igual magnitude possa se repetir a cada 10 anos, ou em cada ano este evento tem $10 \%$ de chance de ocorrer. Adicionalmente, no presente estudo, a análise dos registros de ocorrência, combinada aos dados pluviométricos (ainda que descontínuos do ponto de vista espacial e temporal), sugere um padrão de aumento significativo dos índices de chuva e do número de ocorrências com uma ciclicidade entre $7 \mathrm{e}$ 10 anos, ressalvando porém, que os eventos chuvosos podem ter magnitudes distintas, não sendo possível estimar com clareza o tempo de retorno desses eventos.

ESPANHA (2008) argumenta que, normalmente, os resultados do zoneamento de perigo e de risco à inundação, provenientes de diferentes métodos e escalas de abordagem e representação espacial, não são comparáveis tampouco correlacionáveis entre si, uma vez que as análises e produtos (mapas em especial) têm objetivos e elementos de enfoque distintos. Isso também é apontado por MEYER \& MESSNER (2005), ainda mais quando seus resultados procuram orientar as avaliações de danos e impactos e a priorização de ações e investimentos por parte do Poder Público.

Não obstante, vale citar o trabalho de GRAMANI et al. (2004), que realizou um diagnóstico dos fenômenos de inundação em áreas urbanas de 37 municípios situados no Vale do Rio Paraíba do Sul e Serra da Mantiqueira com o objetivo de subsidiar futuros Planos de Contingência. $\mathrm{O}$ estudo fundamentou-se na utilização de modelos digitais do terreno, a partir dos quais foram obtidas informações sobre as características físicas das principais sub-bacias (com influência sobre as respectivas áreas urbanas), tais como forma, densidade de drenagem, sinuosidade, declividade e amplitude altimétrica. Sugerem os autores que as maiores declividades e a forma arredondada das bacias (como por exemplo, a Sub-Bacia de Cruzeiro) favorecem a rápida concentração das águas superficiais e a ocorrência de inundações repentinas, enquanto em sub-bacias com forma alongada e menores declividades (como a Sub-Bacia de Pindamonhangaba) ocorre o retardamento da vazão e as inundações tendem a ser mais lentas. Pode-se dizer que os resultados do presente estudo corroboram, de forma bastante genérica e limitada, as observações de GRAMANI et al. (2004), pois que na parte sul do Município de Aparecida, onde são maiores os gradientes de declividade e amplitude altimétrica, também foram observados processos com rápida concentração de águas pluviais e formação local de enxurrada, todavia, induzidos pela intervenção antrópica (impermeabilização do solo). Por sua vez, no município de Pindamonhangada, os eventos documentados de inundação no presente estudo, através de vídeos e relatos de moradores e agentes públicos municipais, indicam processos mais lentos de cheia e de transborda- 
mento de margens dos córregos. Por outro lado, as diferenças entre o número de áreas de ocorrência de inundação cadastradas nos municípios estudados em comum são bastante significativas. Por exemplo, GRAMANI et al. (2004) identificaram apenas 3 áreas de risco de inundação em cada um dos municípios de Aparecida e Guaratinguetá, enquanto no presente estudo foram identificadas 13 áreas de risco (com 62 setores) em Aparecida, e 27 áreas (com 135 setores) em Guaratinguetá (IG 2011, 2012a)

Os mapas de risco de inundação procuram incorporar informações sobre ativos e população expostos e sua vulnerabilidade, e podem ser articulados para a resposta à emergência, bem como ferramentas suplementares à tomada de decisão (JHA et al. 2012). Nesse sentido os índices ou escores numéricos obtidos no presente estudo, e, em particular, o Índice de Risco a Inundação (Rinu), permite a hierarquização e comparação entre os diversos setores de risco mapeados (num mesmo município e entre municípios), demonstrando potencial de aplicação à priorização de ações em suporte à tomada de decisão, principalmente quando combinados à estimativa de dano potencial (D).

Observou-se que, em termos proporcionais, o número de setores de risco muito alto e alto é significativamente maior nos municípios do Vale do Paraíba do Sul em relação à São José Rio Preto, aparentemente refletindo a influência de condições geomorfológicas, hidrográficas e socioeconômicas locais. Verifica-se que em São José do Rio Preto o relevo mais suavizado e o padrão socioeconômico (vulnerabilidade mais baixa) refletem-se na predominância de setores de risco moderado e baixo, enquanto no Vale do Rio Paraíba do Sul, a morfologia e as características físicas do terreno (planície aluvial encaixada em formas de relevo com maiores diferenças de elevação altimétrica e declividade) refletem-se nos escores numéricos mais altos e setores de perigo de maior grau, que, combinados a uma ocupação urbana onde predominam tipos e padrões construtivos mais baixos (vulnerabilidade maior), induzem notadamente a um maior número (proporcional) de setores de risco mais alto.

A insuficiência de dados fluvio-pluviométricos e de bases cartográficas mais adequadas estimularam o desenvolvimento do método aqui apresentado, mas por outro lado, representam um limitante a uma abordagem hidrológica mais efetiva, com o uso de modelos numéricos e de procedimentos de análise espacial de dados. Tais procedimentos permitiriam, por exemplo, a estimativa de cotas máximas de inundação, ou de forma experimental, a geração de grades numéricas e o estabelecimento de cotas de atingimento (Cota altimétrica de referência + Nível de atingimento $N A t$ ). Futuros trabalhos de cunho investigativo necessitam também aprofundar aspectos referentes à avaliação probabilística e econômica dos danos potenciais (tangíveis e intangíveis) aos setores de risco delimitados.

\section{AGRADECIMENTOS}

Os autores gostariam de expressar seus agradecimentos nominalmente a Lana Carolina Danna pela colaboração nos trabalhos de campo, sistematização e interpretação de dados; a Tulius Dias Nery, Antônio C. M. Guedes, Pedro Carignato B. Leal, Francis Soares e Osvaldo Coutinho pelo apoio nos trabalhos de geoprocessamento; a Ivete Costa da Silva, Cristiane Barbosa da Silveira, Adalberto Ferreira Barbosa, Roberval Mariano, Valentim Santos Filho e Hernandez Magalhães Filho pelo apoio nos trabalhos de campo; a toda equipe de técnicos e funcionários do Instituto Geológico e aos revisores anônimos da Revista do Instituto Geológico.

\section{REFERÊNCIAS BIBLIOGRÁFICAS}

ANDRADE, E.; DANNA, L.C.; SANTOS, M.L.; FERNANDES DA SILVA, P.C. 2010. Levantamento de ocorrências de inundação em registros de jornais como subsídio ao planejamento regional e ao mapeamento de risco. In: ABGE, SIMPÓSIO BRASILEIRO DE CARTOGRAFIA GEOTÉCNICA, 7, Maringá, Anais, CD-ROM, 10 p.

ANDRADE, E.; DANNA, L.C.; FERNANDES DA SILVA, P.C. 2012. Mapeamento de Perigos e Riscos de Inundação no Município de Aparecida (São Paulo). Anuário do Instituto de Geociências - UFRJ, 35(2): 28-42.

BEVEN, K.; CARLING, P.A. 1989. Floods. Hydrological, Sedimentological and Geomorphological Implications. Wiley and Sons, Chichester, $290 \mathrm{p}$.

BRANDÃO DA SILVA, L.J.R.O.; J.A.F. MENDONÇA. 2007. IQR - Índice Quantitativo de Risco: Uma nova metodologia de cartografia aplicada à Cidade do Rio de Janeiro. In: ABGE, SIMPÓSIO BRASILEIRO DE CARTOGRAFIA GEOTÉCNICA E GEOAMBIENTAL, 6, Uberlândia, Anais, 1: 596-601. 
BRASIL. 2007. Mapeamento de riscos em encostas e margens de rios. Ministério das Cidades/ Instituto de Pesquisas Tecnológicas - IPT, Brasília, 176 p.

BROLLO, M.J.; FERREIRA, C.J.; TOMINAGA, L.K.; VEDOVELLO, R.; FERNANDES DA SILVA, P.C.; ANDRADE, E.; GUEDES, A.C.M. 2011. Situações dos desastres e riscos no Estado de São Paulo e instrumentos de gestão. In: ABGE, CONGRESSO BRASILEIRO DE GEOLOGIA DE ENGENHARIA E AMBIENTAL, 13, São Paulo, Anais, CD-ROM, $10 \mathrm{p}$.

CORREA, E.; RAMIREZ, F.; SANAHUJA, H. 2011. Populations at Risk of Disaster: A Resettlement Guide. The World Bank, GFDRR. Washington, DC, $142 \mathrm{p}$.

DIAS, L.; BRAUNSCHWEIG, F.; GROSSO, N.; COSTA, H.; GARRETT, P. 2014. Guia Metodológico para a Produção de Cartografia de Risco de Inundações. Fundação da Faculdade de Ciências da Universidade de Lisboa. Disponível em: http://cirac. apseguradores.pt/outputs/guia-metodologico/ guia-risco-pt.pdf. Acessado em 5 mai. 2015.

DRUCK, S.; CARVALHO, M.S.; CÂMARA G.; MONTEIRO, A.V.M. 2004. Análise Espacial de Dados Geográficos. EMBRAPA, Brasília, $209 \mathrm{p}$.

ESPANHA. 2008. Guía metodológica para la elaboración de cartografías de riesgos naturales en España: Colegio Oficial de Geólogos de España. Disponível em http:// www.icog.es/riesgos/index.php/guiametodologica-para-la-elaboracion-decartografias-de-riesgos-naturales-en-espana/. Acessado em 23 abr. 2015.

FERNANDES DA SILVA, P.C.; ANDRADE, E.; DANNA, L.C. 2011. Mapeamento de risco à inundação em municípios do Vale do Paraíba (SP): abordagem metodológica para delimitação e caraterização de setores de perigo. In: ABGE, CONGRESSO BRASILEIRO DE GEOLOGIA DE ENGENHARIA E AMBIENTAL, 13, São Paulo, Anais, CD-ROM, 10 p.

FERREIRA, C.J.; OGIHARA, V.H.; VIEIRA, R.E.; BIGANZOLLI, R. 2011. Uso da mídia eletrônica na elaboração de banco de dados de desastres relacionados a eventos geodinâmicos no Estado de São Paulo. In: ABGE, CONGRESSO BRASILEIRO DE GEOLOGIA DE ENGENHARIA, 13, São Paulo, Anais, p. 1-6.

GRAMANI, M.F.; SILVA, F.C.; ALMEIDA FILHO, G.S.; GOUVEIA, M.I.F. 2004. Diagnóstico das inundações em áreas urbanas do Rio Paraíba do Sul e Mantiqueira, SP: Subsídios para o Plano de Contingência. In: GEDN/UFSC, SIMPÓSIO BRASILEIRO DE DESASTRES NATURAIS, 1, Florianópolis, Anais, CD-ROM, p. 539-553.

IG - INSTITUTO GEOLÓGICO. 2008. Mapeamento de Áreas de Risco a Escorregamentos e Inundações do Município de São Luiz do Paraitinga (SP). IG/SMA, São Paulo, 1 v. e mapas, 38 p. (Relatório Técnico).

IG - INSTITUTO GEOLÓGICO. 2011. Mapeamento de riscos associados a escorregamentos, inundações, erosão, solapamento, colapso e subsidência Município de Aparecida - SP. IG/SMA, São Paulo, 3 v. (Relatório Técnico). Disponível em: http://www.sidec.sp.gov.br/producao/ map_risco/pesqpdf3.php?id $=40 . \quad$ Acessado em 19 mai. 2015.

IG - INSTITUTO GEOLÓGICO. 2012a. Mapeamento de riscos associados a escorregamentos, inundações, erosão, solapamento, colapso e subsidência Município de Guaratinguetá - SP. IG/ SMA, São Paulo, 4 v. (Relatório Técnico). Disponível em: http://www.sidec.sp.gov.br/ producao/map_risco/pesqpdf3.php?id=32. Acessado em 19 mai. 2015.

IG - INSTITUTO GEOLÓGICO. 2012b. Mapeamento de riscos associados a escorregamentos, inundações, erosão, solapamento, colapso e subsidência Município de São José do Rio Preto - SP. IG/ SMA, São Paulo, 2 v. (Relatório Técnico). Disponível em: http://www.sidec.sp.gov.br/ producao/map_risco/pesqpdf3.php?id=368. Acessado em 19 mai. 2015.

IPH - INSTITUTO DE PESQUISAS HIDRÁULICAS. 2001. Plano Diretor de Drenagem Urbana de Porto Alegre. Porto 
Alegre, Prefeitura Municipal de Porto Alegre, UFRGS, $5 \mathrm{v}$.

JHA, A.K.; BLOCH, R.; LAMOND, J. 2012. Cidades e Inundações: Um guia para a Gestão Integrada do Risco de Inundação Urbana para o Século XX. The World Bank, Washington, D.C., 49 p.

MADSEN, H.; LAWRENCE, D.; LANG, M.; MARTINKOVA, M.; KJELDSEN, T.R. 2013. European flood-frequency analysis in a changing environment. COST Action ES0901, Centre for Ecology \& Hydrology, United Kingdom, 170 p. Disponível em: http://www.cost-floodfreq.eu. Acessado em 5 mai. 2015.

MAFFRA, C.Q.T.; MAZZOLA, N. 2007. As razões dos desastres em território brasileiro. In: R.F. Santos (org.) Vulnerabilidade Ambiental: Desastres Naturais ou Fenômenos Induzidos? Brasília, Ministério do Meio Ambiente, p. 9-12.

MARCHIORI-FARIA, D.G.; FERREIRA, C.J.; PENTEADO, D.R.; FERNANDES DA SILVA, P. C ; CRIPPS, J.C. 2005. Mapeamento de áreas de risco a escorregamentos e inundações em áreas habitacionais de Diadema (SP) In: ABGE, CONGRESSO BRASILEIRO GEOLOGIA DE ENGENHARIA E AMBIENTAL, 11, Florianópolis, Anais, 1: 892-907.

MERZ, B.; THIEKEN, A. H.; GOCHT, M. 2007. Flood Risk Mapping at the Local Scale: Concepts and Challenges. In: S. Begum; M.J.F. Stive; J.W. Hall, (ed.) Flood Risk Management in Europe. Dordrecht, Netherlands, Springer, p. 231-251.

MEYER, V.; MESSNER, F. 2005. National flood damage evaluation methods - A review of applied methods in England, the Netherlands, the Czech Republic and Germany. Leipzig, Germany, UFZ-Discussion Papers. Disponível em: https://www.ufz.de/export/ data/1/26214_dp212005.pdf. Acessado em 9 abr. 2015 .

MIRANDOLA, F.A.; MACEDO, E.S.; GRAMANI, M.F.; CORSI, A.C.; CANIL, K. 2014. Mapeamento e gerenciamento de áreas de risco de deslizamento e solapamento de margem no município de Santo André, SP. In: UFABC, SEMINÁRIO NACIONAL SOBRE URBANIZAÇÃO DE FAVELAS, 1, São Bernardo do Campo, Anais, 16 p.

PINHEIRO, A. 2003. Modelos de Previsão de Cheias. In: B. Franke \& A. Pinheiro (ed.) Enchentes na Bacia do Itajaí: 20 anos de experiências. Blumenau, Edifurb, p. 93-128.

ROSS, J.L.S; MOROZ, I.C. 1997 Mapa Geomorfológico do Estado de São Paulo (1:500.000). Laboratório de Geomorfologia do Depto de Geografia da FFLCH - USP/ Laboratório de Cartografia Geotécnica Geologia Aplicada. São Paulo: IPT/FAPESP. 18 p: nota explicativa e mapas.

ROSSINI-PENTEADO，D.; FERREIRA，C.J.; GILBERTI, P.P. C. 2007. Quantificação da vulnerabilidade e dano aplicados ao mapeamento e análise de risco, escala 1:10.000, Ubatuba-SP. In: ABGE, SIMPÓSIO BRASILEIRO DE DESASTRES NATURAIS E TECNOLÓGICOS, 2, Santos, Anais, CD-ROM, 10 p.

SOUZA, C.R.G. 2004. Risco a inundações, enchentes e alagamentos em regiões costeiras. In: ABGE/GEDN-UFSC, SIMPÓSIO BRASILEIRO DE DESASTRES NATURAIS, 1, Florianópolis, Anais, 231247.

SOUZA, C.R.G. 2009. Flood risk assessment in coastal drainage basins through a multivariate analysis within a GIS-based model. Journal of Coastal Research, Special Issue, 56, 900904.

TOMINAGA, L.K. 2009. Análise e mapeamento de risco. In: L.K. Tominaga; J. Santoro; R. Amaral (org.) Desastres Naturais: Conhecer para Prevenir. São Paulo, Instituto Geológico, p. $148-160$.

TOMINAGA, L.K.; FERREIRA, C.J.; VEDOVELLO, R.; TAVARES, R.; SANTORO, J.; SOUZA, C.R.G. 2004. Cartas de perigo a escorregamentos e de risco a pessoas e bens do Litoral Norte de São Paulo: conceitos e técnicas. In: ABGE, SIMPÓSIO BRASILEIRO DE CARTOGRAFIA GEOTÉCNICA E GEOAMBIENTAL, 5, São Carlos, Anais, CD-ROM, 205-216. 
TOMINAGA, L.K.; ROSSINI-PENTEADO, D.; FERREIRA, C.J.; VEDOVELLO, R. 2008. Mapeamento de Risco a Escorregamentos na Escala 1:10.000: Abordagem Metodológica Aplicada em Ubatuba, SP. $I n$ : UFMG, SIMPÓSIO NACIONAL DE GEOMORFOLOGIA, 7, Belo Horizonte, Anais, CD-ROM, 10 p.

TUCCI, C.E.M. 2005. Gestão de Águas Pluviais Urbanas. Ministério das Cidades, Global Water Partnership - World Bank, Unesco, 269 p.

\section{UN-ISDR - UNITED NATIONS -} INTERNATIONAL STRATEGY FOR
DISASTER REDUCTION. 2004. Living with Risk: A global review of disaster reduction initiatives. Disponível em http:// www.unisdr.org. Acessado em 20 set. 2014.

UN-ISDR - UNITED NATIONS INTERNATIONAL STRATEGY FOR DISASTER REDUCTION. 2009. Terminology on Disaster Risk Reduction. Disponível em http://www.unisdr.org. Acessado em 17 ago. 2012.

VARNES, D.J. 1984. Landslide Hazard Zonation: Review of Principles and Practice. Unesco Press, Paris, $56 \mathrm{p}$.

\section{Endereço dos autores:}

Paulo Cesar Fernandes da Silva, Eduardo de Andrade e Denise Rossini-Penteado - Instituto Geológico, Secretaria do Meio Ambiente do Estado de São Paulo, Rua Joaquim Távora, 822, CEP 04015-011, São Paulo, SP, Brasil. E-mails: paulo.fernandes@igeologico.sp.gov.br, pfernandes_us@yahoo.co.uk, eduardo@igeologico.sp.gov.br, denise@igeologico.sp.gov.br

Artigo submetido em 4 de fevereiro de 2015, aceito em 26 de maio de 2015. 